\title{
Dynamic and Stochastic Instability and the Unbiased Forward Rate Hypothesis: A Variable Mean Response Approach*
}

\author{
Winston T. Lin \\ State University of New York at Buffalo, U.S.A.
}

Since the mid-1970's, the unbiased forward rate hypothesis (UFRH) of forward and spot exchange rates has been intensively studied and tested with inconclusive and contradictory results. On the basis of the hypothesis, this paper provides variable mean response (VMR) random coefficients models to capture the time-varying and stochastic behavior of the slope coefficient to be referred to as the currency beta, and offers more explicit information concerning the nature of the random disturbance, the specification of the heteroscedastic error, and the existence of linear and quadratic trends. The joint application of several novel statistical and econometric techniques leads to a successful attempt to simultaneously test the behavior of currency betas with respect to randomness, nonstationarity, and shifts in the mean and variance. We find that the UFRH is confirmed when the time horizon is short (one month), but becomes increasingly unreliable when the time horizon is longer (three-month, six-month, and twelve-month), that the currency beta displays randomness and nonstationarity with mean and variance shifts through time, and that the properties of the underlying variation and stochastic patterns of the currency beta differ from currency to currency. The impact of the dynamic and stochastic instability of currency betas on the forecasting of future spot rates is substantial. The VMR variants which account for such instability are capable of generating better forecasts of future spot rates than the original UFRH, especially when the time horizon is longer than one month. The implications for the UFRH as a model of forecasting the future spot rate are discussed in detail (JEL F31, F37, F47, G15).

Keywords: currency betas, five special tests, four-step generalized least squares, mean and variance shifts, the unbiasedness hypothesis, variable-mean-response random coefficients models.

\footnotetext{
${ }^{*}$ The author is indebted to three anonymous referees and the editor-in-charge for their constructive and helpful comments. Financial support from the School of Management, State University of New York at Buffalo, is gratefully acknowledged. The author bears sole responsibility for the contents of this paper.
}

(Multinational Finance Journal, 1999, vol. 3, no. 3, pp. 173-221)

CMultinational Finance Society, a nonprofit corporation. All rights reserved. DOI: $10.17578 / 3-3-2$ 


\section{Introduction}

Previous research on the behavior of forward and spot exchange rates focuses mainly on the analysis of the relationship between the future spot and the forward rate based on the simple efficient market hypothesis of forward exchange markets, often referred to as the unbiased forward rate hypothesis (UFRH) or simply as the unbiasedness hypothesis. The hypothesis specifies that because the forward rate fully reflects available information concerning investors' expectations of the future spot rate, it is an unbiased predictor of the future spot rate [cf. Kohlhagen (1979), Levich (1979a, 1979b), Chiang (1988), and others].

There are ample studies directed to the UFRH. A careful review of the literature leads one to observe that the currencies concerned, sample periods, time horizons, and statistical techniques differ from one study to another. In most cases, the ordinary least squares (OLS) method has been used, or both OLS and the seemingly unrelated regression (SUR) have been applied [e.g., Bilson (1981), Chiang (1988), Edwards (1982), and Fama (1984)]. The empirical tests on the UFRH are essentially inconclusive and contradictory: the UFRH is confirmed in some earlier studies [e.g., Cornell (1977) and Kohlhagen (1975, 1979)], whereas it is rejected in other work [e.g., Bilson (1981), Chiang and Chiang (1987), Fama (1984), Giddy and Dufey (1975), Hansen and Hodrick (1980, 1983), Hsieh (1984), and Levich (1979a)]. Still others have obtained mixed results [e.g., Domowitz and Hakkio (1985), Edwards (1982) and Lin and Chen (1998)].

Most studies are concerned with only one sample period, only one time horizon (mostly one month), and one or more currencies. Thus, confirmation and rejection of the UFRH may depend on different currencies, sample periods, and time horizons under study, as well as the statistical methods used. Barnhart and Szakmary (1991) have argued that the conflicting results found in the literature of tests of the UFRH depend upon the econometric specification used for testing the UFRH and differences in the time period used for estimation. I will demonstrate that the econometric specification and methodology, time periods, time horizons, and dynamic and stochastic instability of the beta coefficient are major sources of the conflicting conclusions.

Most of the above-mentioned studies virtually have been undertaken under the structural homogeneity assumption that the regression coefficient (i.e., the beta or slope) of the UFRH is invariant (nonstochastic or constant and stationary in the absence of mean and 
variance shifts). Very few attempts have been made to investigate the random and dynamic behavior of the beta coefficient of the UFRH and its impact on the forecasting of future spot rates. There are, however, two exceptions. The evidence from Gregory and McCurdy (1984) suggests that a homogeneous structure for testing UFRH should be rejected. Chiang (1988) has tested the UFRH within a stochastic coefficient model estimated by the rolling regression method and has concluded that the constant coefficient hypothesis in the exchange rate regression model is rejected. $\mathrm{He}$ also has conjectured, without providing empirical support, that with the stochastic specification of the beta coefficient underlying the UFRH, the forecasting accuracy of the exchange rate can be improved. Some studies, e.g., Baillie and Bollerslev (1989), Booth and Mustafa (1991), and Lin and Chen (1998), have been concerned with the importance of the stochastics and dynamics of foreign exchange rates, though they are not based directly on the UFRH.

The study of Barnhart and Szakmary (1991) has been devoted to testing the UFRH by providing evidence on unit roots, co-integration, and random coefficients, using a percent change specification. It has concluded that the slope coefficients in regressions testing the UFRH are unstable and follow a persistent trend through time. Choi, Hiraki, and Takezawa (1998) have observed the role of the secular exchange rate trend. These important conclusions support our variable mean response (VMR) approach involving a trend factor.

Finally, some of the empirical studies that have been devoted to the unbiasedness hypothesis have suggested modeling and testing alternatives to the UFRH. The particularly relevant ones include the literature on regime switching [e.g., Engel and Hamilton (1990) and Barnhart and Szakmary (1991)], learning [e.g., Lewis (1989)], signal extraction [Wolff (1987a)], time-varying parameters and forecasting [e.g., Wolff (1987b)], and a simulation analysis [Barnhart, McNown and Wallace (1999)].

The present study pursues a different modeling and testing alternative to the unbiasedness hypothesis in order to examine the stochastics and dynamics of its beta coefficient and implications for forecasting foreign exchange rates. The alternative involves a logarithmic change specification and a VMR process of stochastic and time-varying (dynamic) coefficients. The logarithmic change specification is considered as an appropriate transformation of the $\mathrm{UFRH}$, in view of the fact that spot and forward rates are co-integrated 
[Taylor (1995)] and the fact that there exists the so-called Siegel's (1972) paradox. The motivation for using the VMR regressions to test the UFRH lies in the fact that incorporating a four-step generalized least squares (FGLS) procedure, the VMR models provide an appropriate methodology of simultaneously testing the random and dynamic instability concerning randomness, nonstationarity, and mean and variance shifts of the slope coefficients of the VMR regressions testing the UFRH. Such an in-depth analysis leads to some conclusions that are significant for comprehending the stochastic and dynamic behavior of foreign exchange rates and for forecasting future spot rates.

Therefore, the primary objective of this research is to provide a comprehensive investigation of the stochastic and dynamic instability of the slope coefficients of the regressions testing the UFRH and its implications for forecasting future spot exchange rates. The objective is achieved by applying the novel, powerful modeling and econometric methodologies used in Lin , Chen, and Boot (1992) and Lin and Lin (2000). The methodologies include the VMR process, the FGLS estimation method, and the $T^{*}, B, G, S^{\prime}$, and $W$ tests.

More specifically, to accomplish the specific objective, the specification in which the change in the logarithmic spot rate is regressed onto the logarithmic forward premium is reformulated as a VMR model of random coefficients [Singh et al. (1976), Lin, Chen, and Boot (1992) and Lin and Lin [2000]. It is both appealing and useful from the stochastic, dynamic, and forecasting perspectives to transform the test equation appropriate for the UFRH into a stochastically timevarying coefficients model, which might capture the data-generating process associated with some unspecified class of alternative models.

Then, the FGLS procedure, as proposed by Theil (1971) and Singh et al. (1976) and used in Lin, Chen, and Boot (1992) and Lin and Lin (2000), is applied to estimate the transformed VMR random coefficients models. The hypotheses concerning randomness and nonstationarity (mean and variance shifts) of the slope coefficient are tested. The problem of variance shift (heterogeneity) is analyzed using the $T^{*}[\mathrm{Hsu}$ (1977)], B [Bartlett (1937)], G [Bartlett and Kendall (1946)], S' [Layard (1973)], and W [Brown and Forsythe (1974)] tests. Finally, the VMR models' ability of forecasting future spot rates is assessed against, that is, the impact of the stochastic and dynamic instability of the beta coefficients in the logarithmic change regressions testing the UFRH upon the accuracy of future spot rate forecasts is evaluated against, the UFRH and some of its widely accepted extensions, including an error 
correction model.

The rest of the paper is organized as follows. Section II contains the econometric specification and its VMR reformulation. Section III reports the empirical findings. Section IV provides a discussion of the implications for the UFRH as a model of forecasting future spot rates under the VMR specifications. Section V summarizes the conclusion of the paper with some remarks.

\section{Model Specification and Statistical Hypotheses}

\section{A. The Unbiased Forward Rate Hypothesis and Contradictory Conclusions}

For any currency $j$, the forward exchange rate in period $t$ for delivery in m periods (months), $F_{j, t, m}$, is the market-determined certainty equivalent which is equal to a risk premium $\left(P_{j, t, m}\right)$ plus the expected future spot rate prevailing $\mathrm{m}$ periods (months) in the future $\left(S_{j, t+m}\right)$. Thus, $F_{j, t, m}=$ $P_{j, t, m}+S_{j, t+m}$ or $S_{j, t+m}=-P_{j, t, m}+F_{j, t, m}$. Writing this as a simple linear regression model, we arrive at the well-known unbiased forward rate hypothesis (UFRH). Thus, the UFRH can be described by the nonlogarithmic form: ${ }^{1}$

$$
S_{j, t+m}=a_{j, m}+b_{j, m} F_{j, t, m}+e_{j, t+m}
$$

or, in the logarithmic form,

$$
\ln S_{j, t+m}=a_{j, m}^{\prime}+b_{j, m}^{\prime} \ln F_{j, t, m}+e_{j, t+m}^{\prime}
$$

where $t=1, \ldots, M ; m=1,3,6,12$; and $e_{j, t+m}$ and $e_{j, t+m}^{\prime}$ are random errors with zero means and constant variances. The non-log model 1 and the $\log$ model 1 ' are referred to as the "level" specification. ${ }^{2}$

Another form often used for testing the UFRH is referred to as the "percent change" specification in which the change in the spot rate is

1. See Cornell (1977), Kohlhagen (1979), Levich (1979a), Longworth (1981), Edwards (1982), Fama (1984), Gregory and McCurdy (1984), Chiang (1988), and Barnhart and Szakmary (1991).

2. See Barnhart and Szakmary (1991). 
regressed on the forward premium:

$$
S_{j, t+m}-S_{j, t-1+m}=a_{j, m}^{\prime \prime}+b_{j, m}^{\prime \prime}\left(S_{j, t-1+m}-F_{j, t-1+m, m}\right)+e_{j, t+m}^{\prime \prime} .
$$

If the exchange market is efficient, that is, if the UFRH, also called the unbiasedness hypothesis, holds true, the intercept $a_{j, m}\left(=-P_{j, t, m}\right.$ for all $t, a_{j, m}^{\prime}$, or $a_{j, m}^{\prime \prime}$ ) does not significantly differ from zero and the slope $b_{j, m}\left(b_{j, m}^{\prime}\right.$ or $\left.b_{j, m}^{\prime \prime}\right)$ does not significantly differ from one.

As pointed out by Boothe and Longworth (1986), Barnhart and Szakmary (1991), and others, contradictory results from different specifications have been obtained: those who have tested the UFRH based on the level specification (1) or $\left(1^{\prime}\right)$ have provided evidence supporting the hypothesis, while those who have used the percent change specification (2) have come to the conclusion that the UFRH must be rejected. The conflicting conclusions can easily be explained by the fact that spot and forward rates are characterized by a unit root and are co-integrated. Using both the Dickey-Fuller (1979, 1981), Dickey-Pantula (1987), and Phillips-Perron [Phillips and Perron (1988) and Perron (1988)] tests, Barnhart and Szakmary (1991), Lin and Chen (1998), and innumerable other authors have concluded that the foreign exchange rates (spot and forward) in the level and percent change forms have unit roots, i.e., I (1), and are co-integrated. Co-integration precludes a regression in levels and in pure first differences (i.e., percent changes) because there is no long-run solution [Taylor (1995)]. The appropriate transformation of the UFRH to overcome co-integration involves regressing the change in the logarithmic spot rate onto the logarithmic forward premium or discount [Boothe and Longworth (1986)]:

$$
\begin{gathered}
\ln S_{j, t+m}-\ln S_{j, t-1+m} \\
=\beta_{0 j, m}+\beta_{j, m}\left(\ln S_{j, t-1+m}-\ln F_{j, t-1+m, m}\right)+v_{j, t+m} .
\end{gathered}
$$

This is a very basic practice in the literature of foreign exchanges; in particular, it is standard practice to take logarithms in this literature because of Siegel's (1972) paradox. Equation 3 will be referred to as the "logarithmic change" specification and the beta (slope) coefficient 
of the forward premium as "the currency beta."

Virtually all previous research assumes a time-invariant structure, where the currency betas in regressions (1) or $\left(1^{\prime}\right)$ and (2) remain constant over the entire time span M, implying that the response of the dependent variable to the independent variable is unchanged over the entire time period and, consequently, the point estimators of the currency betas are constant over the sample period. In reality, however, such an assumption of structural homogeneity has been challenged [cf., e.g., Belsley and Kuh (1973), Rosenberg (1973), Collins, Ledolter, and Rayburn (1987), Lin, Chen, and Boot (1992), Pagan (1980), Raj and Ullah (1991), and Lin and Lin (2000)], leading both theorists and practitioners to pay more attention in recent years to stochastically timevarying coefficients models [e.g.,Raj and Ullah (1981), Gregory and McCurdy (1984), Wolff (1987b), Chiang (1988), Lin, Chen, and Boot (1992), and Lin and Lin (2000), among others]. As mentioned earlier, Gregory and McCurdy (1984) and Chiang (1988) have provided empirical evidence which rejects an invariant structure of the test equation 1 or $1^{\prime}$. Barnhart and Szakmary (1991), using the percent change specification (2), have indicated that the evolution of the currency betas is becoming increasingly inconsistent with the UFRH with the passage of time.

If we succeed in capturing the dynamics and stochastics of the currency beta, then the constant UFRH assumption is a serious specification error, i.e., the original UFRH (in non-log or log form) is misspecified and may cause serious consequences in the pricing and forecasting of future spot rates [cf. Ghysels (1998) and Lin and Lin (2000)]. Thus, in order to comprehend the UFRH more fully and precisely and forecast future spot rates more accurately, I find it necessary to investigate the stochastic and dynamic instability of the currency beta of the logarithmic change specification testing the UFRH and its effect on the forecasting of future spot rates within the framework of the VMR random coefficients model which, as mentioned before, provides an appropriate methodology of simultaneously testing the hypotheses concerning randomness, nonstationarity, mean shift, and variance shift of the currency beta $\left(\beta_{j, m}\right)$ of equation $3 .^{3}$

3. According to Rosenberg (1973), there are two types of parameter variation: dynamic (systematic) and stochastic. Both types must be considered jointly [Belsley and Kuh (1973)]. 


\section{B. The VMR Random Coefficients Transformation of the UFRH}

The VMR model is a specification of randomly time-varying coefficients and includes the constant mean response (CMR) random coefficients model proposed by Hildreth and Houck (1968) as a special case.

Assuming that in equation 3 , the intercept $\left(\beta_{0, j, m}\right)$ is constant, the spot rate change is $Y_{j, m}(t)=\ln S_{j, t+m}-\ln S_{j, t-1+m}$ and the previous period's forward premium is $X_{j, m}(t-1)=\ln S_{j, t-1+m}-\ln F_{j, t-1+m, m}$, we can transform equation 3 into a VMR model of stochastic coefficients:

$$
\begin{gathered}
Y_{j, m}(t)=\beta_{0 j, m}+\beta_{j, m}(t) X_{j, m}(t-1)+v_{j, m}(t) \\
\beta_{j, m}(t)=\beta_{j, m}+\alpha_{j, m} f_{j, m}(t)+u_{j, m}(t),
\end{gathered}
$$

where $\beta_{j, m}$ and $\alpha_{j, m}$ are constant but unknown coefficients independent of time $\mathrm{t} ; f_{j, m}(t)$ is a function of $t$; and $v_{j, m}(t)$ and $u_{j, m}(t)$ are random disturbances with $E\left[v_{j, m}(t)\right]=E\left[u_{j, m}(t)\right]=0$, and $E\left[v_{j, m}(t) v_{j, m}(s)\right]=\sigma_{v j, m}^{2}$ and $E\left[u_{j, m}(t) u_{j, m}(s)\right]=\sigma_{u j, m}^{2}$ for all $t=s$ and 0 for all $t \neq s$. Accordingly, the random coefficient $\beta_{j, m}(t)$ is distributed with $E\left[\beta_{j, m}(t)\right]=\beta_{j, m}+$ $\alpha_{j, m} f_{j, m}(t)$ and $\operatorname{Var}\left[\beta_{j, m}(\mathrm{t})\right]=\sigma_{u j, m}^{2}$.

Equation 5 assumes that the random currency beta is a function of time. The theory behind the assumption is called the VMR random coefficients theory [Theil (1971) and Singh et al. (1976)], an extension of the constant mean response (CMR) random coefficients model [Hildreth and Houck (1968)]. This assumption suggests that the variable mean of the random currency beta, that is, $E\left[\beta_{j, m}(t)\right]=d Y_{j, m}(t) /$ $d X_{j, m}(t-1)=\beta_{j, m}+\alpha_{j, m} f_{j, m}(t)$, is decomposed into two components: the constant beta $\left(\beta_{j, m}\right)$ and the product of the function of $t$ and its coefficient $\left(\alpha_{j, m} f_{j, m}(t)\right)$. Thus, under the VMR theory, the conditional expectation of the currency beta is the same as the exchange rate change caused by the change in the previous period's forward premium.

Furthermore, as implied by the VMR specifications of equations 4 and 5, there are two essential sources of random variation: the error in equation, $v_{j, m}(t)$, and the error in the randomly time-varying currency beta, $u_{j, m}(t)$. A significant estimate of $\sigma_{u j, m}^{2}$ indicates that the currency beta of currency $j$ is moving stochastically. According to equation 5, the behavior of the stochastic and dynamic beta, $\beta_{j, m}(t)$, is subject to two 
influences that cause it to deviate from its mean value, $\beta_{j, m}$. One source is the influence of the dynamic factor $f_{j, m}(t)$, which may vary systematically with time $(t)$ and represents the impact of various economic causes on the currency beta. The other source is the influence of the random disturbance, $u_{j, m}(t)$, which has certain probability distributional properties. The former is deterministic while the latter is stochastic. $^{4}$

Note that the intercept in equation 3 is assumed to be constant. There are two major reasons why the constancy assumption is made. One reason is that our focus is on the dynamic and stochastic properties of the currency beta in equation 3 used for testing the UFRH and their impacts on the forecasting of future spot rates, rather than on the market efficiency per se; in other words, our interest lies in the stochastically time-varying behavior of the currency beta and its impact on improved point forecasting of future spot rates. More importantly, the other compelling reason is that, as pointed out by Singh et al. [(1976), p. 342], Raj and Ullah [(1981), p. 69], and Lin, Chen, and Boot [(1992), p. 520], a serious identification problem will result from the joint presence of a randomly time-varying intercept with the random error, $v_{j, m}(t)$, in equation 4 . Assuming a constant intercept in equation 4 is required to overcome the identification of the variance of $v_{j, m}(t)$, $\sigma_{v j, m}^{2}$.

Though we have cited the reasons of focus and methodology (identification) to impose the constancy assumption on the intercept $\left(\beta_{0}\right)$, we must note that the constant term in the regression is the risk premium, and caution that, in the literature, it is known that the exchange rate risk premium is likely to be time-varying and persistent [Wolff (1973) and Cheung (1993)]. Longworth (1981) has assumed no risk premium while testing the efficiency of the Canadian-U.S. exchange market. Kaminsky and Peruga (1990) have questioned whether a time-varying risk premium explains excess returns in the forward market. Bekaert and Hodrick (1993) have investigated two sources of bias in the measurement of foreign exchange risk premium: measurement error and specification error arising from an omitted variable problem and a parameter instability problem. All of these studies seem to point to the same question concerning the time-varying

4. For more information concerning explanations of the theoretical VMR specification, see Singh et al. (1976) and Lin, Chen, and Boot (1992). 
characteristics of the intercept. If the constant term is statistically zero (the case when $m=1,3$, according to our empirical results), then the issue of time-varying risk premium is of no concern to us. If, however, it is statistically different from zero (the case when $m=6,12$ as the empirical results indicate), then the assumption may imply a source of specification error and, consequently, may bias any conclusion on the UFRH. How serious is it? This is an empirical matter [Bekaert and Hodrick (1993)] open for future research as the methodology (identification) problem can be resolved. Until the impact of the assumption has been accurately assessed, it is premature to reject it.

Upon substituting equation 5 into equation 4, the VMR random coefficients representation of equation 3 testing the UFRH becomes:

$$
\begin{gathered}
Y_{j, m}(t)=\beta_{0 j, m}+\beta_{j, m} X_{j, m}(t-1) \\
+\alpha_{j, m} f_{j, m}(t) X_{j, m}(t-1)+w_{j, m}(t)
\end{gathered}
$$

where $w_{j, m}(t)=u_{j, m}(t) X_{j, m}(t-1)+v_{j, m}(t)$ is a composite error with a zero conditional mean and a conditional variance equal to $E\left[w_{j, m}(t) w_{j, m}(s)\right]$ $=X_{j, m}^{2}(t-1) \sigma_{u j, m}^{2}+\sigma_{v j, m}^{2}$ for all $t=s$ and $=0$ for all $t \neq s$. Thus, the composite errors are heteroscedastic and also serially uncorrelated if the random errors, $v_{j, m}(t)$ and $u_{j, m}(t)$, are serially uncorrelated. In the estimation process, I apply the Newey-West (1987) adjustment procedure to cope with the possibility of serial correlation (see Section III B. below).

It is noted that $\beta_{j, m}(t)$ is random if $\sigma_{u j, m}^{2}$ differs significantly from 0 , and is nonstationary if $\alpha_{j, m}$ differs from 0 . When $\sigma_{u j, m}^{2}=\alpha_{j, m}=0$, the VMR random coefficients heteroscedastic model 6 collapses to the logarithmic change specification (3) testing the UFRH, i.e., to the constant coefficients homoscedastic regression model. The randomness issue of $\beta_{j, m}(t)$ leads to the heteroscedastic composite error $w_{j, m}(t)$ that complicates the estimation of equation 6, thereby entailing the application of the FGLS procedure. Fortunately, the nonstationarity issue causes no complication in estimating the VMR model 6. For simplicity, the currency index $\mathrm{j}$ will be omitted from now on.

As stated earlier, Barnhart and Szakmary (1991) and Choi, Hiraki, and Takezawa (1998) have found the importance of a persistent trend through time in their tests of the UFRH, based on the level and percent 
change specifications, i.e., equations 1 and 2 . The trend variable is built in the VMR transformation (6). The function $f_{m}(t)$ in equation 6 may take any form; for example, a linear form, a parabolic form, an exponential form, etc. ${ }^{5}$ I briefly describe three special cases as follows. ${ }^{6}$ (Note that a hat $\left(^{\wedge}\right)$ will be placed above a variable or a parameter to denote a fitted value or an estimate obtained by the FGLS procedure.)

Case 1: $f_{m}(t)=0$, the error-in-beta or pure randomness case

When the economic trends causing the beta coefficient to vary systematically do not exist, the $f_{m}(t)$ function disappears from the VMR model 4- 5 or 6 , and $\beta_{m}(t)$ shifts only with the random disturbance component over time, and equation 5 becomes

$$
\beta_{(R) m}(t)=\beta_{(R) m}+u_{(R) m}(t)
$$

where $u_{(R) m}(t)$ is distributed with a zero mean and a constant variance equal to $\sigma_{u(R) m}^{2}$ and equation 6 reduces to: ${ }^{7}$

$$
Y_{(R) m}(t)=\beta_{0(R) m}+\beta_{(R) m} X_{m}(t-1)+w_{(R) m},
$$

where $w_{(R) m}(t)=u_{(R) m}(t) X_{m}(t-1)+v_{(R) m}(t)$ is the heteroscedastic error with a zero conditional mean and a conditional dynamic or variable variance equal to $X_{m}^{2}(t-1) \sigma_{u(R) m}^{2}+\sigma_{v(R) m}^{2}$. The statistical significance of the FGLS estimate $\hat{\sigma}_{u(R) m}^{2}$ implies that the currency beta is random rather than fixed, and that both the error in the currency beta, $u_{(R) m}(t)$,

5. In practice, the form of $f_{m}(t)$ should be determined by the sample information, i.e., estimate a VMR regression model with different forms of $f_{m}(t)$ and choose the form which yields the highest $R^{2}$ value [Singh et al. (1976)]. It suffices to consider the three special forms of $f_{m}(t)$ as described in Lin, Chen, and Boot (1992) and Lin and Lin (2000); the functional forms of $f_{m}(t)$ with orders higher than two yield no results that are statistically acceptable, due possibly to the problem of multicollinearity.

6. See Lin, Chen, and Boot (1992) and Lin and Lin (2000) for more details.

7. Note that model 8 is the constant mean response (CMR) random coefficients model proposed by Hildreth and Houck (1968) and later used by Fabozzi and Francis (1978) and Theil (1971). Hence, the VMR family (6) includes the CMR model 8 as a special case. 
and the error in the equation, $v_{(R) m}(t)$, are the sources of randomness that cause the response of the currency's change in the spot rate to vary stochastically with the forward premium through time.

Case 2: $f_{m}(t)=t$, the linear trend or linearly dynamic case

If there is a simple upward or downward economic trend, then $f_{m}(t)$ can be represented by a simple linear form or $f_{m}(t)=t$. Under this specification, equations 4 - 6 yield

$$
\begin{gathered}
\beta_{(D) m}(t)=\beta_{(D) m}+\alpha_{(D) m} t+u_{(D) m}(t), \\
Y_{(D) m}(t)=\beta_{0(D) m}+\beta_{(D) m} X_{m}(t-1) \\
+\alpha_{(D) m} X_{m}(t-1)+w_{(D) m}(t),
\end{gathered}
$$

where $X_{m}^{*}(t)=t X_{m}(t-1)$ and $w_{(D) m}(t)=u_{(D) m}(t) X_{m}(t-1)+v_{(D) m}(t)$. Note that the conditional mean and the conditional variance of $u_{(D) m}(t)$ are zero and $\sigma_{u(D) m}^{2}$, respectively, whereas those of $w_{(D) m}(t)$ are zero and $X_{m}^{2}(t-1) \sigma_{u(D) m}^{2}+\sigma_{v(D) m}^{2}$, respectively.

Significant FGLS estimates $\hat{\alpha}_{(D) m}^{2}$ and $\hat{\sigma}_{u(D) m}^{2}$ indicate that the currency beta involves a linear trend (upward or downward, depending on whether $\hat{\alpha}_{(D) m}^{2}$ is positive or negative) and is random. However, if $\hat{\alpha}_{(D) m}^{2}$ is not significantly different from zero, case 2 reduces to case 1 .

\section{Case 3: $f_{m}(t)=t+t^{2}$, the parabolic trend or parabolically dynamic case}

If the cyclical fluctuations of the currency beta during the upturn and downturn are symmetric for a certain time period, then its time path of movements can be approximated by a parabolic trend. In this case, the $f_{m}(t)$ function takes a quadratic form and the VMR formulation is given by:

$$
\beta_{(P) m}(t)=\beta_{(P) m}+\alpha_{(P) m} t+\gamma_{(P) m} t^{2}+u_{(P) m}(t),
$$




$$
\begin{gathered}
Y_{(P) m}(t)=\beta_{0(P) m}+\beta_{(P) m} X_{m}(t-1)+\alpha_{(P) m} X_{m}^{*}(t-1) \\
\gamma_{(P) m} X_{m}^{* *}(t-1)+w_{(P) m}(t),
\end{gathered}
$$

where $X_{m}^{*}(t-1)=t X_{m}(t-1), X_{m}^{* *}(t-1)=t^{2} X_{m}(t-1)$, and $w_{(P) m}(t)$ $=u_{(P) m}(t) X_{m}(t-1)+v_{(P) m}(t)$. The conditional mean and the conditional constant variance of $u_{(P) m}(t)$ are zero and $\sigma_{u(P) m}^{2}$, respectively, while the composite error, $w_{(P) m}(t)$, has a zero conditional mean and a conditional dynamic or variable variance equal to $X_{m}^{2}(t-1) \sigma_{u(P) m}^{2}+\sigma_{v(P) m}^{2}$. The conditional variance of $u_{(P) m}(t)$ is constant, but the conditional variance of $w_{(P) m}(t)$ changes over time.

When neither $\hat{\alpha}_{(P) m}$ nor $\hat{\gamma}_{(P) m}$ is statistically significant, this case reduces to case 1 . If only $\hat{\alpha}_{(P) m}$ is significant, then it collapses to case 2. In general, significant FGLS estimates, $\hat{\beta}_{(P) m}, \hat{\alpha}_{(P) m}$, and $\hat{\gamma}_{(P) m}$, yield an estimated VMR function of the currency beta equal to $\hat{\beta}_{(P) m}(t)$ $=\hat{\beta}_{(P) m}+\hat{\alpha}_{(P) m} t+\hat{\gamma}_{(P) m} t^{2}$, which represents a class of parabolas with vertical axes parallel to the $\hat{\beta}_{(P) m}(t)$ axis and with vertices located at

$$
V\left(-\hat{k}_{(P) m},-\hat{d}_{(P) m}\right) \text {, where } \hat{k}_{(P) m}=\hat{\alpha}_{(P) m} / 2 \hat{\gamma}_{(P) m},
$$

and

$$
\hat{d}_{(P) m}=\left(\hat{\alpha}_{(P) m}^{2}-4 \hat{\beta}_{(P) m} \hat{\gamma}_{(P) m}\right) / 4 \hat{\gamma}_{(P) m},
$$

[Lin,Chen, and Boot (1992, p. 523) and see figures 1 and 2 below].

\section{Statistical Hypotheses}

Given that the functional form of $f_{m}(t)$ is more or less pre-specified as being at most quadratic, the hypotheses under interest should be nested, i.e.,

$$
\begin{aligned}
& H 1 \quad \text { with } H_{0}: \gamma_{(P) m}=0, \alpha_{(P) m} \neq 0 \text {, and } \sigma_{u(P) m} \neq 0 \text { versus } H_{1}: \gamma_{(P) m} \\
& \quad \neq 0, \alpha_{(P) m} \neq 0 \text {, and } \sigma_{u(P) m} \neq 0 \\
& H 2 \text { with } H_{0}: \alpha_{(D) m}=0 \text {, and } \sigma_{u(D) m} \neq 0 \text { versus } H_{1}: \alpha_{(D) m} \neq 0 \text {, and } \\
& \\
& \sigma_{u(D) m} \neq 0
\end{aligned}
$$


$H 3$ with $H_{0}: \sigma_{u(R) m}=0$ versus $H_{1}: \sigma_{u(R) m} \neq 0$.

In such a way, the time periods and currencies that do not statistically reject $H_{1}$ in $\mathrm{H} 1$ should not be tested for hypothesis $\mathrm{H} 2$ or $\mathrm{H} 3$; and the time periods and currencies that reject $H_{1}$ in $\mathrm{H} 1$ should be tested for hypothesis $\mathrm{H} 2$. If the time periods and currencies do not reject $H_{1}$ in $\mathrm{H} 2$, they should not be tested for hypothesis H3. Finally, the time periods and currencies that reject $H_{1}$ in $\mathrm{H} 2$ should be tested for hypothesis H3. In such a way it should be apparent at the end how many out of 300 cases belong to the four possible parameterizations of $\beta_{m}(t)$, with the fourth one being the non-stochastic $\beta_{m}(t)$, i.e., $\beta_{m}(t)=\beta_{m}$.

If the alternative hypothesis of $\mathrm{H} 1$ is not rejected but the alternative hypotheses of $\mathrm{H} 2$ and $\mathrm{H} 3$ are rejected, it is a clear sign of time and random variations in the form of quadratic (parabolic) trends. If the alternative hypotheses of $\mathrm{H} 1$ and $\mathrm{H} 3$ and the null hypothesis of $\mathrm{H} 2$ are rejected, it signals the existence of randomly changing patterns in the form of linear trends. Finally, rejecting the null hypotheses of H1, H2, and $\mathrm{H} 3$ makes the error-in-beta or pure randomness case. The validity of the UFRH requires rejection of all three alternative hypotheses and, simultaneously, $\beta_{(R) m}, \beta_{(D) m}$, and $\beta_{(P) m}$ do not significantly differ from one, assuming that the constant term is statistically zero.

\section{Empirical Results}

\section{A. The Data}

The forward and spot exchange rates (expressed in terms of U.S. dollars) of five currencies were collected from The Wall Street Journal. The five currencies are the British pound (BP), German mark (GM), Japanese yen (JY), Canadian dollar (CD), and Swiss franc (SF). Four time horizons, $m=1,3,6,12$ month, and fifteen (15) time periods, $1 / 1973$ to $12 / 1987,4 / 1973$ to $1 / 1980,1 / 1974$ to $8 / 1984,1 / 1974$ to $12 / 1979,4 / 1973$ to $7 / 1979,1 / 1974$ to $12 / 1984,1 / 1977$ to $12 / 1987$, $1 / 1981$ to $12 / 1987,8 / 1978$ to $12 / 1987,1 / 1981$ to $12 / 1987,1 / 1973$ to $12 / 1998,1 / 1977$ to $12 / 1998,1 / 1981$ to $12 / 1998,1 / 1988$ to $12 / 1998$, and $1 / 1989$ to $12 / 1998$, were considered.

While the length of a sub-period is randomly determined, the choice of the sub-periods is not entirely arbitrary. The first ten periods have been used by other authors [e.g., Chiang (1988) and Gregory and 
McCurdy (1984)]. The last five periods are used to update the data used in previous research. The eleventh period, 1/1973 to 12/1998, represents the whole sample period considered for the present study.

Using both the Dickey-Fuller (1979, 1981), Dickey-Pantula (1987), and Phillips-Perron [Phillips and Perron (1988) and Perron (1988)] tests, we are able to conclude that the foreign exchange rates (spot and forward) for all five currencies considered have unit roots and, hence, are I (1). The results are consistent with the conclusions reached by many authors, including Barnhart and Szakmary (1991), Taylor (1995), Bhawnani and Kadiyla (1997), and Lin and Chen (1998). Therefore, the logarithmic change specification (3) is an appropriate transformation of the UFRH [Taylor (1995)].

\section{B. Estimation Methods}

Following traditional tests on the simple efficient market theory, equation 3 is first estimated by both the OLS and SUR methods for purpose of comparison. Since there exist composite errors in equations 8, 10, and 12, neither OLS nor SUR is valid for estimating these equations. Instead, they are estimated by the FGLS method. As mentioned before, the FGLS is a modified version of the HildrethHouck's (1968) four-step method (which is appropriate for case 1 only). A brief description of the stepwise procedure is given in appendix I.

With monthly data and 3-, 6- and 12-month forward contracts, we have to cope with an overlapping data problem [Hansen and Hodrick (1980)], which causes the error terms to be autocorrelated. Thus, the autocorrelation (serial correlation) problem cannot be simply assumed away. In particular, if the errors $v_{j, m}(t)$ in equation 4 or 6 are autocorrelated, the problem of overlapping data or autocorrelation does not vanish. The problem can be solved by using a Newey-West (1987) adjustment to the variance-covariance matrices in the OLS, SUR, and FGLS procedures.

\section{Five Tests for Variance Shift}

To detect variance shifts or heterogeneity, five special tests, known as $T^{*}$ [Hsu (1977)], B [Bartlett (1937)], G [Bartlett and Kendall (1946)], S' [Layard (1973)], and W [Brown and Forsythe (1974)], are performed. While these tests are well documented, they are outlined and presented in appendix II.

The true currency beta functions needed to perform the five special 
tests can be derived from equations 7 to12 as follows:

$$
\begin{gathered}
\beta_{(R) m}(t)=\hat{\beta}_{(R) m}+\hat{u}_{(R) m}(t), \\
\beta_{(D) m}(t)=\hat{\beta}_{(D) m}+\hat{\alpha}_{(D) m} t+\hat{u}_{(D) m}(t), \\
\beta_{(P) m}(t)=\hat{\beta}_{(P) m}+\hat{\alpha}_{(P) m} t+\hat{\gamma}_{(P) m} t^{2}+\hat{u}_{(P) m}(t),
\end{gathered}
$$

where

$$
\hat{u}_{(R) m}(t)=Y_{m}(t)-\hat{Y}_{(R) m}(t),
$$

with

$$
\begin{gathered}
\hat{Y}_{(R) m}(t)=\hat{\beta}_{0(R) m}+\hat{\beta}_{(R) m} X_{m}(t-1), \\
\hat{u}_{(D) m}(t)=Y_{m}(t)-\hat{Y}_{(D) m}(t),
\end{gathered}
$$

with

$$
\begin{gathered}
\hat{Y}_{(D) m}(t)=\hat{\beta}_{0(D) m}+\hat{\beta}_{(D) m} X_{m}(t-1)+\hat{\alpha}_{(D) m} X_{m}^{*}(t-1), \\
\hat{u}_{(P) m}(t)=Y_{m}(t)-\hat{Y}_{(P) m}(t),
\end{gathered}
$$

with

$$
\begin{aligned}
& \hat{Y}_{(P) m}(t)=\hat{\beta}_{0(P) m}+\hat{\beta}_{(P) m} X_{m}(t-1) \\
& +\hat{\alpha}_{(P) m} X_{m}^{*}(t-1)+\hat{\gamma}_{(P) m} X_{m}^{* *}(t-1),
\end{aligned}
$$

and $Y_{m}(t), X_{m}^{*}(t-1)$, and $X_{m}^{* *}(t-1)$ are as defined in equations 4,10 , and 12. According to the VMR theory, equations 13 to 15 indicate that the true currency beta functions are equal to the sum of a deterministic component and the observed residual between the actual and the fitted 
spot rate change. For example, equation 15 follows from equations 11 and 12 and indicates that the true currency beta under the parabolic trend specification is constituted by two factors: the deterministic component, which is the FGLS estimate of the deterministic part, $\beta_{(P) m}$ $+\alpha_{(P) m} t+\gamma_{(P) m} t^{2}$, of equation 11, and the fitted residual, which is the difference between the actual $Y_{m}(t)$ and the fitted $\hat{Y}_{(P) m}(t)$ of equation 12, again obtained by FGLS [see Theil (1971), Singh et al. (1976), Lin, Chen, and Boot (1992), and Lin and Lin (2000)]. Note that the same actual $Y_{m}(t)$ applies to Equations 13 to 15 .

Because the $B, G, S^{\prime}$ and $W$ tests are based on group data, it is necessary to divide the true currency betas from equations $13-15$ into K groups, each having $n_{k}$ values such that $\sum_{k} n_{k}=M$; and the $n_{k}$ values in the $k$-th group are further randomly divided into $J_{k}$ subgroups, each having $m_{g}$ values such that $\sum_{g} m_{g}=n_{k}$. Details of the grouping of the true betas used in the present study are shown in table 1 .

\section{The OLS and SUR Results}

The OLS and SUR results for regressions (3) are not shown here to save space. SUR achieved higher efficiency than OLS. However, both the OLS and SUR estimates of currency betas are positive and strongly indicate that the UFRH is generally confirmed for the horizon of one month $(m=1)$; the results are mixed for $m=3$ month; and the UFRH is totally rejected for $m=6$ month and 12 month. In other words, the UFRH becomes shaky and skeptical as the time horizon lengthens. The statistical problem of autocorrelation also becomes increasingly serious as $m$ increases. More specifically, when $m=1$, the absence of serial correlation was confirmed, except for the period 1/1973 - 12/1987, as indicated by the Durbin-Watson test statistics. When $m=3,6$, and 12, however, it appears that there exists a positive autocorrelation problem. In particular, when $m=6$ and 12 , the problem is serious and cannot be ignored. Such an autocorrelation or overlapping data problem was resolved by applying the Newey-West (1987) adjustment to the variance-covariance matrix. The empirical evidence suggests that previous research may suffer from deficiency in its empirical tests since previous tests were confined to either $m=1$ or 3 only and, consequently, the conclusions drawn from the tests are inapplicable to $m=6$ and 12 . The empirical evidence also suggests that there is a need for an 
TABLE 1. Grouping of $\beta_{(i) m}(t), i=R, D, P$

Period No. Sample Period Grouping

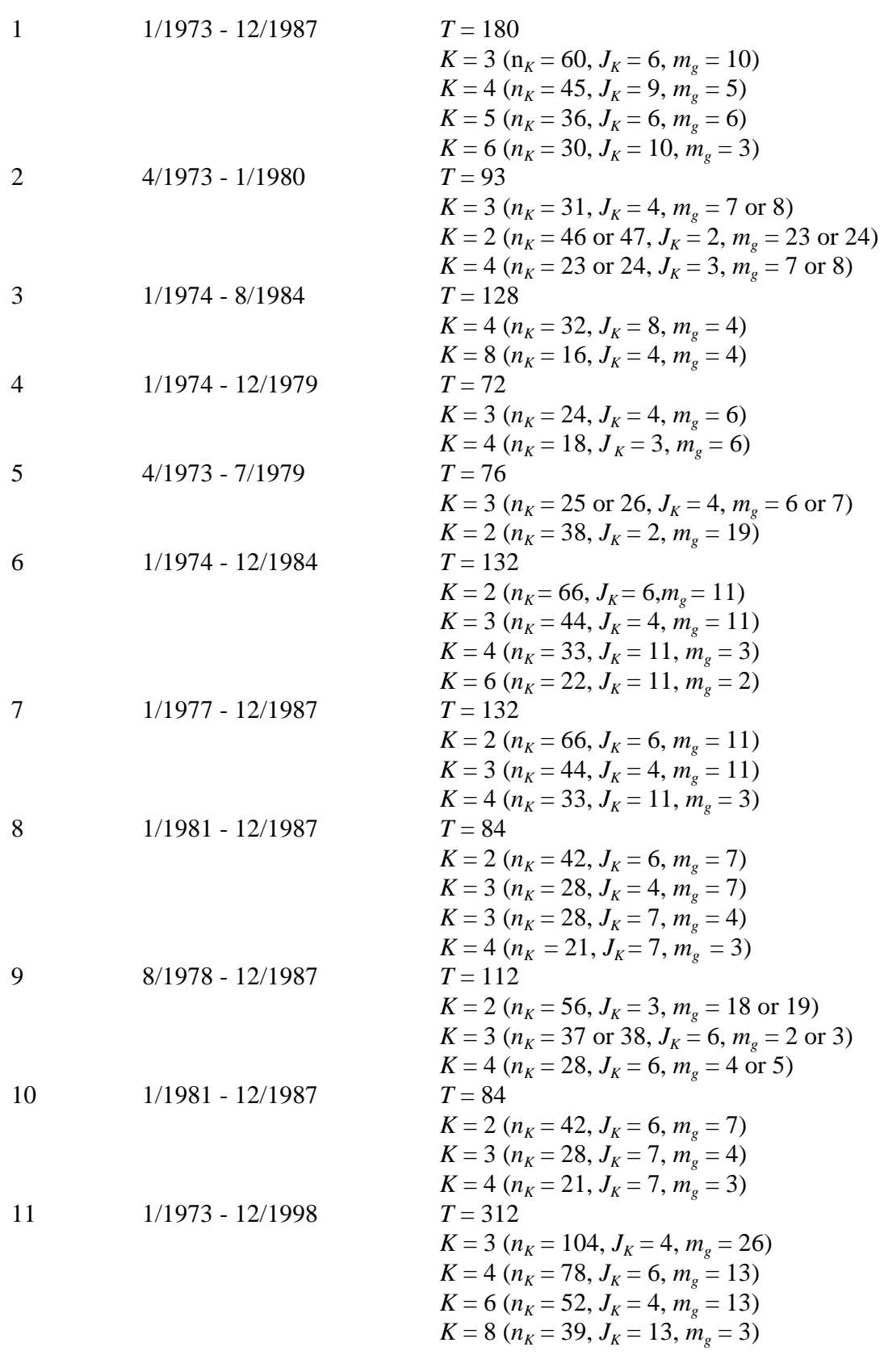


TABLE 1. (Continued)

\begin{tabular}{|c|c|c|}
\hline Period no. & Sample Period Grouping & \\
\hline 12 & 1/1977 - 12/1998 & $\begin{array}{l}T=264 \\
K=3\left(n_{K}=88, \mathrm{~J}_{K}=4, m_{\mathrm{g}}=20\right) \\
K=4\left(n_{K}=66, \mathrm{~J}_{K}=6, m_{\mathrm{g}}=11\right) \\
K=6\left(n_{K}=44, \mathrm{~J}_{K}=11, m_{\mathrm{g}}=4\right) \\
K=8\left(n_{K}=33, \mathrm{~J}_{K}=11, m_{\mathrm{g}}=3\right)\end{array}$ \\
\hline 13 & 1/1981 - 12/1998 & $\begin{array}{l}T=216 \\
K=3\left(n_{K}=72, \mathrm{~J}_{K}=4, m_{\mathrm{g}}=18\right) \\
K=4\left(n_{K}=54, \mathrm{~J}_{K}=6, m_{\mathrm{g}}=9\right) \\
K=6\left(n_{K}=36, \mathrm{~J}_{K}=4, m_{\mathrm{g}}=9\right) \\
K=8\left(n_{K}=27, \mathrm{~J}_{K}=3, m_{\mathrm{g}}=9\right)\end{array}$ \\
\hline 14 & $1 / 1988-12 / 1998$ & $\begin{array}{l}T=132 \\
K=2\left(n_{K}=66, \mathrm{~J}_{K}=6, m_{\mathrm{g}}=11\right) \\
K=3\left(n_{K}=44, \mathrm{~J}_{K}=4, m_{\mathrm{g}}=11\right) \\
K=4\left(n_{K}=33, \mathrm{~J}_{K}=11, m_{\mathrm{g}}=3\right)\end{array}$ \\
\hline 15 & $1 / 1989-12 / 1998$ & $\begin{array}{l}T=120 \\
K=2\left(n_{K}=60, \mathrm{~J}_{K}=6, m_{\mathrm{g}}=10\right) \\
K=3\left(n_{K}=40, \mathrm{~J}_{K}=5, m_{\mathrm{g}}=8\right) \\
K=4\left(n_{K}=30, \mathrm{~J}_{K}=3, m_{\mathrm{g}}=10\right)\end{array}$ \\
\hline
\end{tabular}

intensive investigation of the dynamic and stochastic behavior of the currency beta as reflected by its response to structural shifts over time caused by changes of market and economic conditions across countries (currencies).

\section{E. The FGLS Results}

The FGLS estimates of parameters in models 8, 10, and 12 were obtained. The corresponding $t$-statistics, the adjusted coefficient of determination $\left(\bar{R}^{2}\right)$, and the Durbin-Watson statistic were calculated.

Based on the grouping of $\beta_{(i) m}(t)$ from equations 13 to 15 , the test values of $T^{*}, B, G, S^{\prime}$, and $W$ were also calculated. Table 2 reports FGLS estimates, $m=1$ : one time period per currency, ${ }^{8}$ and table 3 presents the results of the statistical tests on the hypotheses $\mathrm{H} 1, \mathrm{H} 2$, and $\mathrm{H} 3$. The $\bar{R}^{2}$ s obtained by FGLS were high in most cases. However, like the OLS and SUR results, the value of $\bar{R}^{2}$ decreases as $m$ increases from 1 to 12 . FGLS, incorporating with the Newey-West adjustment, has

8. It is not possible to include all the detailed results here under the constraint of space. 
TABLE 2. FGLS Estimates, $m=1$ : One Time Period Per Currency

\begin{tabular}{|c|c|c|c|c|c|c|c|}
\hline Time Period Currency & Equation & $\beta_{0}$ & $\beta$ & $a$ & $\gamma$ & $\sigma_{(I)}$ & $\bar{R}^{2}$ \\
\hline \multirow{4}{*}{$\begin{array}{l}1 / 19 \text { C49 } \\
8 / 1984 \\
\text { (Period 3) }\end{array}$} & -.0031 & .9996 & - & - & .0003 & .9855 & \\
\hline & & $(-.21)$ & $(790.3)$ & & & $(1.07)$ & \\
\hline & 10 & $\begin{array}{l}-.0004 \\
(-.12)\end{array}$ & $\begin{array}{l}1.008 \\
(378.3)\end{array}$ & $\begin{array}{l}-.0003 \\
(-.94)\end{array}$ & - & $\begin{array}{l}.0004 \\
(1.04)\end{array}$ & .9854 \\
\hline & 12 & $\begin{array}{l}-.012 \\
(-.45)\end{array}$ & $\begin{array}{l}1.0043 \\
(248.1)\end{array}$ & $\begin{array}{l}-.00015 \\
(-1.05)\end{array}$ & $\begin{array}{l}.0000009 \\
(.84)\end{array}$ & $\begin{array}{l}.0007 \\
(1.00)\end{array}$ & .9858 \\
\hline \multirow{3}{*}{$\begin{array}{l}1 / 1974- \\
12 / 1984 \\
\text { (Period 6) }\end{array}$} & 8 & $\begin{array}{c}-.0094 \\
(-1.07)\end{array}$ & $\begin{array}{c}.996 \\
(377.7)\end{array}$ & - & - & $\begin{array}{l}.0025 \\
(8.47)\end{array}$ & .9513 \\
\hline & 10 & $\begin{array}{l}-.0176 \\
(-1.09)\end{array}$ & $\begin{array}{l}1.0087 \\
(190.4)\end{array}$ & $\begin{array}{l}-.00016 \\
(-2.76)\end{array}$ & - & $\begin{array}{l}.0024 \\
(6.01)\end{array}$ & .9529 \\
\hline & 12 & $\begin{array}{l}-.0151 \\
(-1.02)\end{array}$ & $\begin{array}{l}1.0099 \\
(126.9)\end{array}$ & $\begin{array}{l}-.00022 \\
(-5.78)\end{array}$ & $\begin{array}{l}.0000004 \\
(.2)\end{array}$ & $\begin{array}{l}.0031 \\
(5.70)\end{array}$ & .9523 \\
\hline \multirow{3}{*}{$\begin{array}{l}1 / 1981- \\
12 / 1987 \\
\text { (Period 8) }\end{array}$} & 8 & $\begin{array}{l}-.0001 \\
(-.79)\end{array}$ & $\begin{array}{l}1.0115 \\
(183.9)\end{array}$ & - & - & $\begin{array}{l}.0033 \\
(4.32)\end{array}$ & .9692 \\
\hline & 10 & $\begin{array}{l}.0834 \\
(.81)\end{array}$ & $\begin{array}{l}1.0508 \\
(357.0)\end{array}$ & $\begin{array}{l}-.00235 \\
(-3.65)\end{array}$ & - & $\begin{array}{l}.0035 \\
(4.85)\end{array}$ & .9393 \\
\hline & 12 & $\begin{array}{l}.0002 \\
(1.02)\end{array}$ & $\begin{array}{l}.953 \\
(90.6)\end{array}$ & $\begin{array}{l}.00327 \\
(6.42)\end{array}$ & $\begin{array}{l}-.0000358 \\
(-9.68)\end{array}$ & $\begin{array}{l}.0037 \\
(4.73)\end{array}$ & .9631 \\
\hline
\end{tabular}




\section{TABLE 2. (Continued)}

\begin{tabular}{|c|c|c|c|c|c|c|c|c|}
\hline 1/19דSF & (8) & .0123 & 1.0006 & - & - & .001 & .9616 & \\
\hline $12 / 1998$ & & & (1.49) & $(400.2)$ & & & $(2.88)$ & \\
\hline (Period 11) & & (10) & $\begin{array}{c}.0174 \\
(1.34)\end{array}$ & $\begin{array}{c}1 \\
(194.9)\end{array}$ & $\begin{array}{l}.00001 \\
(4.13)\end{array}$ & - & $\begin{array}{l}.0012 \\
(2.96)\end{array}$ & .9614 \\
\hline & & (12) & $\begin{array}{l}.0063 \\
(.38)\end{array}$ & $\begin{array}{l}1.0172 \\
(129.4)\end{array}$ & $\begin{array}{l}-.00054 \\
(-2.77)\end{array}$ & $\begin{array}{l}.000003 \\
(2.9)\end{array}$ & $\begin{array}{l}.0015 \\
(2.79)\end{array}$ & .9622 \\
\hline 1/19\$P & (8) & -.0708 & .9972 & - & - & .0009 & .9684 & \\
\hline $12 / 1998$ & & & $(-1.24)$ & (377.5) & & & $(2.98)$ & \\
\hline (Period 15) & & (10) & $\begin{array}{l}-.0239 \\
(-1.36)\end{array}$ & $\begin{array}{c}1.0083 \\
(189.5)\end{array}$ & $\begin{array}{l}-.00017 \\
(-2.41)\end{array}$ & - & $\begin{array}{l}.0011 \\
(3.4)\end{array}$ & .9702 \\
\hline & & (12) & $\begin{array}{l}-.0361 \\
(-.59)\end{array}$ & $\begin{array}{c}.9961 \\
(123.4)\end{array}$ & $\begin{array}{l}.00038 \\
(1.35)\end{array}$ & $\begin{array}{l}-.00038 \\
(-2.01)\end{array}$ & $\begin{array}{l}.0013 \\
(3.35)\end{array}$ & .9709 \\
\hline
\end{tabular}

Note: Student $t$ - values are given in parentheses just below the parameter estimates; and $\sigma_{(i)}$ is the standard error of the currency beta, $i=R, D$, $P$. 
TABLE 3. Statistical Tests

\begin{tabular}{|c|c|c|c|c|c|c|c|c|c|c|c|c|c|c|c|c|c|c|c|}
\hline \multirow[b]{2}{*}{ Period No. } & \multicolumn{6}{|c|}{ H1 } & \multicolumn{6}{|c|}{$\mathrm{H} 2$} & \multicolumn{6}{|c|}{$\mathrm{H} 3$} & \multirow[b]{2}{*}{ Total } \\
\hline & $\mathrm{CD}$ & GM & JY & $\mathrm{SF}$ & BP & Sub Total & $\mathrm{CD}$ & GM & JY & SF & BP & Sub Total & $\mathrm{CD}$ & GM & JY & $\mathrm{SF}$ & BP & SubTotal & \\
\hline 1 & 3 & 3 & 1 & 2 & 2 & 11 & 1 & 1 & 2 & 2 & 0 & 6 & 0 & 0 & 1 & 0 & 0 & 1 & 18 \\
\hline 2 & 3 & 1 & 1 & 1 & 0 & 6 & 1 & 2 & 1 & 1 & 0 & 5 & 0 & 0 & 1 & 1 & 0 & 2 & 13 \\
\hline 3 & 1 & 1 & 3 & 0 & 1 & 6 & 2 & 1 & 1 & 3 & 2 & 9 & 1 & 1 & 0 & 1 & 2 & 5 & 20 \\
\hline 4 & 2 & 3 & 2 & 1 & 0 & 8 & 0 & 0 & 2 & 0 & 1 & 3 & 1 & 1 & 0 & 2 & 0 & 4 & 15 \\
\hline 5 & 1 & 0 & 1 & 1 & 0 & 3 & 1 & 1 & 2 & 0 & 1 & 5 & 1 & 1 & 1 & 2 & 1 & 6 & 14 \\
\hline 6 & 0 & 1 & 2 & 1 & 0 & 4 & 0 & 2 & 0 & 2 & 2 & 6 & 3 & 1 & 2 & 0 & 1 & 7 & 17 \\
\hline 7 & 1 & 2 & 1 & 3 & 0 & 7 & 2 & 0 & 2 & 1 & 1 & 6 & 1 & 1 & 1 & 0 & 0 & 3 & 16 \\
\hline 8 & 2 & 0 & 2 & 1 & 1 & 6 & 1 & 2 & 1 & 2 & 2 & 8 & 1 & 2 & 1 & 1 & 1 & 6 & 20 \\
\hline 9 & 1 & 1 & 1 & 1 & 2 & 6 & 2 & 1 & 2 & 1 & 1 & 7 & 1 & 1 & 1 & 1 & 0 & 4 & 17 \\
\hline 10 & 2 & 2 & 0 & 1 & 2 & 7 & 1 & 2 & 3 & 1 & 0 & 7 & 0 & 0 & 1 & 1 & 1 & 3 & 17 \\
\hline 11 & 2 & 1 & 1 & 1 & 1 & 6 & 1 & 2 & 2 & 1 & 2 & 8 & 0 & 1 & 0 & 2 & 0 & 4 & 18 \\
\hline 12 & 2 & 1 & 2 & 2 & 1 & 8 & 2 & 1 & 2 & 1 & 1 & 7 & 0 & 2 & 0 & 1 & 1 & 4 & 19 \\
\hline 13 & 1 & 1 & 1 & 1 & 2 & 6 & 1 & 1 & 2 & 2 & 1 & 7 & 1 & 2 & 1 & 1 & 1 & 6 & 19 \\
\hline 14 & 0 & 0 & 2 & 2 & 1 & 5 & 2 & 3 & 1 & 2 & 1 & 9 & 1 & 0 & 1 & 0 & 1 & 3 & 17 \\
\hline 15 & 1 & 1 & 0 & 1 & 1 & 4 & 1 & 1 & 1 & 1 & 2 & 6 & 1 & 1 & 2 & 1 & 1 & 6 & 16 \\
\hline Total & 22 & 18 & 20 & 19 & 14 & 93 & 18 & 20 & 24 & 20 & 17 & 99 & 12 & 14 & 13 & 14 & 11 & 64 & 256 \\
\hline
\end{tabular}

Note: (i) Each entry represents the number of time horizons (out of four horizons) rejecting the null hypothesis. (ii) The total numbers of cases rejecting the null hypotheses of $\mathrm{H} 1, \mathrm{H} 2$, and $\mathrm{H} 3$ are $93(31 \%), 99(33 \%)$, and $64(21.3 \%)$, respectively. Consequently, the number out of 300 cases belonging to the fourth parameterization of $\beta_{m}(t)$, i.e., the non-stochastic $\beta_{m}(t)=\beta_{m}$, is $44(14.7 \%)$ 
removed the problem of autocorrelation and has achieved more efficiency and higher explanatory power than both OLS and SUR.

All of the FGLS estimates, $\hat{\beta}_{(R) m}, \hat{\beta}_{(D) m}$, and $\hat{\beta}_{(P) m}$ from models 8 , 10 , and 12 were statistically significant at the $5 \%$ and/or the $1 \%$ level except for the CD in the cases of (8) and (10) for 4/1973 to 1/1980 with $m=3,6,12$; and in the case of (12) for $1 / 1973$ to $12 / 1987$ and

$1 / 1973$ to $12 / 1998$ with $m=12,4 / 1973$ to $1 / 1980$ with $m=1,3,12$, and $1 / 1974$ to $12 / 1979$ with $m=3,6$. As one would expect, almost all of the FGLS estimates are positive with only four exceptions, e. g., -0.6857 for the CD in the case of (10) for 4/1973 to $1 / 1980$ with $m=12$.

The tests of the UFRH based on the logarithmic change specification indicate the importance of a persistent trend through time, a finding consistent with Barnhart and Szakmary (1991) and Choi, Hiraki, and Takezawa (1998), who have tested the UFRH based on the level and percent change specifications.

In the next three subsections that follow, we present a concise summary of the parameter estimates by discussing the dynamic and stochastic behavior of the currency beta in terms of stochastic movements in subsection $F$, nonstationarity and mean shift in subsection $\mathrm{G}$, and nonstationarity and variance shift (or heterogeneity) in subsection $\mathrm{H}$. The first two issues can be resolved by making reference to the three statistical hypotheses, whereas the third issue can be resolved based on the $T^{*}, B, G, S^{\prime}$, and $W$ tests. The final subsection is devoted to an analysis of the impacts of the dynamic and stochastic behavior of the currency beta on the forecasting of future spot rates, i.e., forecasting ability is assessed in subsection I.

\section{F. Pure Randomness and Stochastic Movements}

The third statistical hypothesis (H3) concerns the randomness of the currency beta in the pure randomness case, equations 7 and 8. An inspection of table 3 reveals several important implications:

(i) The empirical evidence indicates that the true currency beta under the logarithmic change specification testing the UFRH is moving randomly for a significant number (64) or $21.3 \%$ of the total cases and is heteroscedastic.

(ii) Period 6 records the highest number (7) of cases, while Period 1 shows the lowest number (1), in favor of the alternative hypothesis. 
(iii) The GM and SF show the highest number (14) of cases in favor of the alternative hypothesis, while the $\mathrm{BP}$ records the lowest number (11) of cases rejecting the null hypothesis of $\mathrm{H} 3$.

(iv) No specific relationships between the length of the time horizon $(m)$ and the number of cases in favor of the alternative hypothesis have been discovered.

\section{G. Nonstationarity and Mean Shifts}

The most interesting feature of the VMR stochastic model is that it enables us to take account of both the random and systematic changes in structural parameters even when we are unable to explicitly recognize the underlying causal factors. Here, I analyze the problem of nonstationarity in terms of mean shifts over time on the basis of the first (H1) and second (H2) statistical hypotheses.

First, we consider $\mathrm{H} 2$ relative to equations 9 and 10 by referring to the FGLS estimates $\hat{\beta}_{(D) m}$ and $\hat{\alpha}_{(D) m}$ of $\beta_{(D) m}$ and $\alpha_{(D) m}$, respectively. The null hypothesis about beta being constant and stationary is rejected for 99 out of 300 cases (33\%).

When the null hypothesis is statistically rejected, the estimated VMR of the currency beta is given by $\hat{\beta}_{(D) m}(t)=\hat{\beta}_{(D) m}+\hat{\alpha}_{(D) m} t$. As an illustration, consider the SF during the 1/1974 - 12/1979 period with $m=12$. The estimated VMR function of the currency beta for this currency was found to be:

$$
\hat{\beta}_{(D) 12}(t)=\begin{array}{rr}
1.1375-.00221 t \\
(27.74)(-2.86)
\end{array}
$$

This estimated VMR function shows that the mean of the currency's beta shifts negatively with time, implying that the currency beta follows a negative (downward sloping) trend and confirming Barnhart and Szakmary's (1991) iterative SUR results of an error correction model. The size of the mean shift was $-.00221 t$ and the marginal rate of the mean shift was -.00221. As a result, in December 1974, the beta estimate was 1.11098 and, in September 1979, it was .98501, while the averaged estimate for the entire period was 1.05790, in comparison with the constant OLS estimate of 1.1874 applied to all 72 months in the sample period. The average of the variable FGLS estimates is much 
closer to one than the OLS estimate. Nevertheless, the UFRH is rejected by both the OLS estimate and the average of the variable FGLS estimates. A similar analysis can equally well be applied to the SF during the $1 / 1973$ to $12 / 1998$ period with $m=1$, where the time-varying beta function was given by:

$$
\hat{\beta}_{(D) 1}(t)=\underset{(194.9)}{1}+.00001 t
$$

implying that the currency beta displays a positive (upward sloping) trend pattern.

Second, we turn to $\mathrm{H} 1$ relative to equations 11 and 12 and the FGLS estimates $\hat{\beta}_{(P) m}, \hat{\alpha}_{(P) m}$, and $\hat{\gamma}_{(P) m}$ of $\beta_{(P) m}, \alpha_{(P) m}$, and $\gamma_{(P) m}$, respectively. It was found that both $\hat{\alpha}_{(P) m}$ and $\hat{\gamma}_{(P) m}$ differ significantly from zero for 93 out of $300(31 \%)$. When the alternative hypothesis is not rejected at the $1 \%$ or $5 \%$ level of significance, the estimated VMR function of the currency beta is given by $\hat{\beta}_{(P) m}(t)=\hat{\beta}_{(P) m}+\hat{\alpha}_{(P) m} t+\hat{\gamma}_{(P) m} t^{2}$. Taking the GM for the 1/1973 - 12/1987 period with $m=3$ as an illustration, we have the currency's estimated beta function represented by:

$$
\hat{\beta}_{(P) 3}(t)=\frac{1.0469-.00152 t+.0000086 t^{2}}{(67.91)(-4.35)}
$$

The beta estimates for December 1973 and December 1987 were 1.0299 and 1.0519, respectively, and the period's averaged estimate was 1.0132; and OLS yielded a slightly under-estimate of .9997, though very close to one. The results suggest that the OLS estimate is consistent with, and the variable FGLS estimates violate, the requirement of the UFRH that the slope be insignificantly different from one for the time period under consideration.

Figure 1 shows the OLS estimate and the estimated currency beta function with vertex located at $V(88.3721, .9797)$, which occurred approximately in April 1980. Note that the beta function is quadratic and, therefore, its curve is a parabola; and, because the coefficient (.0000086) of $t^{2}$ is positive, the parabola opens upwards, as described by figure 1 .

In addition, as given in table 2 , when $m=1$, the beta function of the 


\section{Place Figure 1 Here}

FIGURE 1.-The time path of mean shift of the beta coefficient of the German mark, $1 / 1973$ to $12 / 1987$, compared to the OLS estimate

GM for the $1 / 1974$ to $12 / 1984$ period based on equations 11 and 12 was given by :

$$
\hat{\beta}_{(P) 1}(t)=\begin{array}{ccc}
1.0099- & .00022 t+.0000004 t^{2} \\
(126.9) & (-5.78)
\end{array}
$$

in which the coefficient of $t^{2}$ is not significant.

Consider another example dealing with the JY for the 1/1974 $8 / 1984$ subperiod with $m=1$. The estimated currency beta function was:

$$
\hat{\beta}_{(P) 1}(t)=\underset{(124.64)}{.9299+(9.64)}+.00327 t+.0000246 t^{2}
$$

But the OLS counterpart was .9996, again very close to one, for the period. While the OLS estimate does not tend to suggest rejecting of the UFRH, the FGLS estimates do reject it. The OLS estimate and the observed beta function are shown in figure 2 . We can observe that the vertex of the parabola situated at $V(66.4634,1.0385)$ occurred 


\section{Place Figure 2 Here}

FIGURE 2.-The time path of mean shift of the beta coefficient of the Japanese yen, 1/1974 to 8/1984, compared to the OLS

approximately in June 1979 and, since the coefficient (-.0000246) of $t^{2}$ is negative, the curve (parabola) opens downwards, as depicted by figure 2 .

Besides, table 2 shows that when $m=1$, the time-varying beta function of the JY for the $1 / 1981$ to $12 / 1987$ period was given by:

$$
\hat{\beta}_{(P) 1}(t)=\underset{(90.6) \quad(6.42) \quad(-9.68)}{.953+.00327 t-.0000358 t^{2}}
$$

Again, this function represents a parabola which opens downwards and tends to reject the UFRH. Furthermore, it is of interest to point out that for the two time subperiods with $m=3,6$, and 12, both the OLS estimates and the variable FGLS estimates firmly reject the UFRH.

In both figures 1 and 2, the constant OLS estimates (very close to one) seem to suggest the validity of the UFRH and, on the contrary, the variable FGLS estimates clearly reject it. This is obviously mistaken. In using OLS, currency betas are treated as constants, whereas in using FGLS, they are viewed as randomly time-varying variables. The difference between the assumptions underlying the OLS and the FGLS is substantial substantially. As we can observe from figures 1 and 2, 
because of the dynamic and stochastic behavior of the currency beta, the UFRH is confirmed only at two points in time ( points $C$ and $D$ in figure 1 and points $A$ and $B$ in figure 2) where the parabolic curve intersects the horizontal line drawing from the vertical axis with a value of one.

Figures 1 and 2 portray the changing pattern of a currency beta as a parabolic trend, i.e., the currency beta moves parabolically. Thus, figures 1 and 2 imply that the currency beta is shifting from time to time, rather than fixed as viewed by the level specification (1) or $\left(1^{\prime}\right)$ and the present change specification (2). These figures illustrate such shifting patterns.

Eight points summarize the results under $\mathrm{H} 1$ and $\mathrm{H} 2$ reported in table 3:

(i) The currency beta shows nonstationarity in the sense of mean shifts and randomness for a substantial number $(192=93+99$ or $64 \%=31 \%+33 \%$ ) of the total of 300 cases considered. This nonstationarity takes the form of a linear trend more frequently than a parabolic trend (99 vs. 93 or $33 \%$ vs. $31 \%$ ). In only $44(14.7 \%$ ) ut of 300 cases, currency betas were found to be fixed rather than dynamic and stochastic.

(ii) The number of cases with significant estimates of $\alpha_{(D) m}$ increases as $\mathrm{m}$ increases (i.e., as the time horizon lengthens). The number of cases with significant estimates of $\alpha_{(P) m}$ and $\gamma_{(P) m}$ also increases as $m$ increases.

(iii) The JY reveals the highest number (24) of cases, while the BP shows the lowest number (17), in favor of the alternative hypothesis of $\mathrm{H} 2$, Moreover, the $\mathrm{CD}$ records the highest number (22) of cases where the alternative hypothesis of $\mathrm{H} 1$ is not rejected and, again, the $\mathrm{BP}$ wins the lowest number (14) of cases rejecting the null hypothesis of $\mathrm{H} 1$.

(iv) In H1, Period 1 and, in H2, Periods 3 and 14, record the highest numbers (11 and 9, respectively) of cases in which the alternative hypothesis is not rejected. On the other hand, under H1, period 5 and, under H2, Period 4 have the lowest numbers (3 and 3, respectively) of cases in which the alternative hypothesis is not rejected.

(v) The estimates of $\alpha$ and $\gamma$ change across different time periods. But they do not vary systematically across different time periods, nor do they change over time, under the VMR specifications.

(vi) Apparently, the trending behavior (both linear and quadratic) is 
not stable across sample periods. Such a phenomenon can be explained by equation 5 . As we had noted earlier, according to equation 5 , the dynamic and stochastic behavior of the currency beta, $\beta(t)$, is affected by two forces: one force is generated by the impact of trend conditions [represented by $f(t)$ ] on $\beta(t)$ and the other comes from the influence of the random disturbance. The trend and uncertain conditions differ from period to period. More importantly, these two forces represent two types of parameter variation (i.e., systematic or dynamic and stochastic); and the interaction of these two forces causes the trending behavior (dynamic and stochastic) to be unstable. This explains why Rosenberg (1973) and Belsley and Kuh (1973) have emphasized that both types of variation must be considered jointly.

(vii) Generally speaking, no particular relationships between the number of the significant estimates of $\alpha_{(D) m}, \alpha_{(P) m}$ and $\gamma_{(P) m}$, and the length of the estimation period, were found.

(viii) The test results provide substantial evidence suggesting that observed currency betas exhibit statistically significant time variations. The presence of nonstationarity in the sense of mean shifts implies that the UFRH is misspecified. In other words, the dynamic and stochastic response of the currency beta to structural changes suggests that, in forward exchange markets, the forward rate is not an unbiased predictor of the future spot rate, especially when $m=3,6,12$. This, in turn, implies that in the empirical context, the UFRH may be a multiple, rather than a simple, regression, with a heteroscedastic and autocorrelated error; or it may be specified to be a nonlinear form. (These issues will be discussed in Section IV below.)

\section{H. Nonstationarity and Variance Shifts}

In this subsection I test the phenomenon of nonstationarity in the sense of variance shift or heterogeneity, based on the five special tests, $T^{*}, B$, $S^{\prime}, G$, and $W$. Various economic reasons and unpredictable factors may cause the variance of the currency beta of the forward premium variable in the logarithmic change specification used to test the UFRH to shift over time.

The calculated statistics of the five special tests are given in table 4 . The summary results reveal several points of interest: 
TABLE 4. Summarized Results of Five Special Tests

\begin{tabular}{llllll}
\hline \multicolumn{2}{l}{ VMR Model $T^{*}(\%)$} & $B(\%)$ & $S^{\prime}(\%)$ & $G(\%)$ & $W(\%)$ \\
\hline 8 & 27.7 & 78.3 & 69.5 & 28.6 & 67.7 \\
10 & 30.7 & 62.2 & 60.8 & 24.8 & 62.1 \\
12 & 30.2 & 79.4 & 70.6 & 30.4 & 68.3 \\
\hline
\end{tabular}

Note: (i) Each entry represents the percentage of rejecting the variance homogeneity hypothesis. (ii) Models 8, 10, and 12 represent the pure randomness, the linear, and the parabolic case, respectively.

(i) According to the $B, S^{\prime}$, and $W$ tests, the null hypothesis of the absence of variance shifts in the currency beta was rejected for a majority of cases. For example, in the case of pure randomness, where the random error of the currency beta is incorporated into the VMR transformation, the alternative hypothesis of variance shift or heterogeneity was not rejected by the B test at the $5 \%$ level of significance for $78.3 \%$ of the total cases considered. The percentage was $69.5 \%$ and $67.7 \%$ by means of the $S^{\prime}$ and $W$ tests, respectively. However, the $T^{*}$ and $G$ tests recorded a relatively low percentage of rejecting the null hypothesis.

(ii) Based on the $B, S^{\prime}, G$, and $W$ tests, we can readily observe that there is a strong tendency that the percentage of rejecting the variance homogeneity hypothesis increases as the value of $\mathrm{m}$ increases, i.e., as the time horizon becomes longer. For example, consider the pure randomness case. The null hypothesis was rejected by the $S^{\prime}$ test for $49.1 \%, 61.6 \%, 78.5 \%$, and $89.9 \%$ for $m=$ $1,3,6$, and 12 , respectively, at the $5 \%$ level of significance.

(iii) In general, the parabolic model 12 produces the highest percentage of rejecting the variance homogeneity hypothesis and the linear model 10 records the smallest ratio. The tests are sensitive to the changes in the estimation period and the values of $K$ and $n_{k}$ at various degrees, but no specific tendency is found.

In summary, strong evidence provided by the five tests suggests that the dynamic phenomenon of variance shift or heterogeneity of the currency beta under the logarithmic change specification does exist. The variance shift or heterogeneity is additional evidence of the random and dynamic behavior of currency betas, suggesting that the forward rate may not be an unbiased predictor of the future spot rate in practice. 


\section{Forecasting Ability}

In this subsection, I compare the forecasting performance of the random and time-varying regression models 8,10 , and 12 under the logarithmic change specification with that of the standard regression models 1 or $1^{\prime}$ (the level specification) and model 2 (the percent change specification), as well as their popular extension:

$$
S_{j, t+m}=a_{j}+b_{j} F_{j, t, m}+c_{j}\left(S_{j, t+m}-F_{j, t+m, m}\right)+e_{j, t+m},
$$

or, in the logarithmic form

$$
\begin{gathered}
\ln S_{j, t+m}=a_{j}^{\prime}+b_{j}^{\prime} \ln F_{j, t, m} \\
+c_{j}^{\prime}\left(\ln S_{j, t+m}-\ln F_{j, t+m, m}\right)+e_{j, t+m}^{\prime} .
\end{gathered}
$$

In addition, based on their tests on the level, percent change, and error correction models, Barnhart and Szakmary (1991) have concluded that an error correction model (ECM) is an appropriate specification. Thus, I also consider the following ECM tested by them:

$$
\begin{gathered}
S_{j, t+m}-S_{j, t-1+m}=\alpha_{0, j}+\alpha_{1, j}\left(S_{j, t-1+m}-F_{j, t-1+m, m}\right) \\
+\alpha_{2, j}\left(S_{j, t-6+m}-S_{j, t-7+m}\right)+\alpha_{3, j}\left(F_{j, t-5, m}-F_{j, t-6, m}\right)+\varrho_{j, t+m}
\end{gathered}
$$

All of the time periods used to estimate the VMR models under the logarithmic change specification were used to assess the performance of forecasting. The ex-post forecasts were generated for the two years beyond each of the 15 sample periods. Because of the statistical data available, the last five periods (i.e., periods 11-15) must be shortened by two years, with 12/1996 being the end point, so that we can generate expost forecasts for the two years beyond 1996. Then, the ex-post forecasts were compared with the actual exchange rates.

To judge the forecasting ability of these models, three common measures of forecast accuracy were used. These are the mean absolute deviation (MAD), the root mean squared error (RMSE), and the mean absolute percentage error (MAPE) expressed in percentage. To save space, I report the evaluation results of MAPE only for period 1 in table 
5. The results for other periods lead to the same conclusions. Here I provide a concise summary as follows.

First, overall, in all horizons, the random and dynamic models 8,10 , and 12 outperform the standard model 1 or $1^{\prime}$ and its extended models of fixed coefficients $2,16,17$, and 18 , by all three measurement criteria used. The forecasting results reflect the power of the preceding statistical tests.

Second, more frequently, the parabolically dynamic model 12 appears to forecast future spot rates more accurately than the linearly dynamic model 10 and the purely random model 8; and model 10 appears to have a greater strength than model 8. These forecasting results are consistent to the testing ones and the power of the tests.

Third, the accuracy measures reveal that ECM (18) performs better than models 1 or $1^{\prime}, 2,16$, and 17 , while model 16 or 17 outperforms model 1 or $1^{\prime}$.

Fourth, more specifically, when $m=1$, the champion is model 8 for $\mathrm{CD}, \mathrm{SF}$, and/or BP, is model 10 for GM and/or BP, and is model 12 for $\mathrm{JY}$ and/or CD. When $m=3,6$, the winner is model 8 or 10 for about two-thirds of the currencies considered, followed by model 12 . When $m=12$, model 12 ranks the best for more than two-thirds of the currencies under review, followed by model 10, which is trailed by model 8.

Finally, in most cases, the differences between the MAD, RMSE, and MAPE measures are not substantial. There were very few cases with significant differences between these three criteria, e.g., the JY case when $m=6$ based on models 8,10, and 12) and the SF and BP cases when $m=12$ associated with models $1,2,16$, and 18 .

I have shown that the currency beta is both time-varying and stochastic (64\%) and purely stochastic $(21.3 \%)$, rather than fixed (only $14.7 \%)$. The results of the forecast accuracy evaluation further support our argument that currency betas are both dynamic and random, and such variation characteristics are highly relevant for improved point forecasting of future spot rates. In other words, the assessment results strongly suggest that reformulating the UFRH into a VMR dynamic and stochastic model increases the power of forecasting and improves the accuracy of future spot rate forecasts. The empirical evidence also lends support to Chiang's (1988) observation (without empirical results provided by him) that the random specification of the slope of the UFRH would possibly improve the accuracy of forecasting future spot rates based on the UFRH. 
TABLE 5. Evaluation of Forecast Accuracy: 1/1973 - 12/1987 (Period 1)

\begin{tabular}{|c|c|c|c|c|c|c|c|c|c|c|c|c|c|c|c|}
\hline \multirow{2}{*}{$\begin{array}{l}\text { Time } \\
\text { Horizon }\end{array}$} & \multirow{2}{*}{\multicolumn{2}{|c|}{ Currency Equatior }} & \multirow{2}{*}{$\begin{array}{l}\text { MAPE } \\
(\%)\end{array}$} & \multirow{2}{*}{$\begin{array}{l}\text { Time } \\
\text { Horizon }\end{array}$} & \multirow{2}{*}{\multicolumn{3}{|c|}{$\begin{array}{l}\text { MAPE } \\
\text { Currency Equation }(\%)\end{array}$}} & \multirow{2}{*}{\multicolumn{4}{|c|}{$\begin{array}{l}\text { Time } \quad \text { MAPE } \\
\text { Horizon Currency Equation }(\%)\end{array}$}} & \multirow{2}{*}{\multicolumn{4}{|c|}{$\begin{array}{l}\text { Time MAPE } \\
\text { Horizon Currency Equation }(\%)\end{array}$}} \\
\hline & & & & & & & & & & & & & & & \\
\hline \multirow[t]{21}{*}{$\mathrm{m}=1$} & $\mathrm{CD}$ & (8) & .3309 & $\mathrm{~m}=3$ & $\mathrm{CD}$ & (8) & .9646 & $\mathrm{~m}=6$ & $\mathrm{CD}$ & (8) & 1.8486 & $\mathrm{~m}=12$ & $\mathrm{CD}$ & (8) & 3.7603 \\
\hline & & (10) & .6137 & & & (10) & 1.3484 & & & (10) & 1.9449 & & & (10) & 3.5000 \\
\hline & & (12) & .5149 & & & (12) & .9454 & & & (12) & 1.8460 & & & (12) & 2.5393 \\
\hline & & (1) & .8070 & & & (1) & 1.4454 & & & (1) & 2.3766 & & & (1) & 4.1692 \\
\hline & & (2) & .8069 & & & (2) & 1.5120 & & & (2) & 2.4003 & & & (2) & 4.2134 \\
\hline & & (16) & .8073 & & & (16) & 1.4395 & & & (16) & 2.3766 & & & (16) & 4.1700 \\
\hline & & (18) & .8068 & & & (18) & 1.4410 & & & (18) & 2.3800 & & & (18) & 4.0279 \\
\hline & GM & (8) & 2.0252 & & GM & (8) & .2031 & & GM & (8) & .4758 & & GM & (8) & 1.6723 \\
\hline & & (10) & .0615 & & & (10) & .2041 & & & (10) & .5674 & & & (10) & 1.3062 \\
\hline & & (12) & 3.8622 & & & (12) & .9565 & & & (12) & 3.8810 & & & (12) & 5.6437 \\
\hline & & (1) & 4.2547 & & & (1) & 1.0009 & & & (1) & 5.5827 & & & (1) & 14.8934 \\
\hline & & (2) & 4.2438 & & & (2) & 1.0021 & & & (2) & 5.5712 & & & (2) & 15.0073 \\
\hline & & (16) & 4.2024 & & & (16) & 1.0015 & & & (16) & 5.5436 & & & (16) & 15.1002 \\
\hline & & (18) & 3.9800 & & & (18) & 1.0008 & & & (18) & 5.2503 & & & (18) & 14.5028 \\
\hline & JY & (8) & .4392 & & JY & (8) & .7368 & & JY & (8) & 2.1575 & & JY & (8) & 11.9495 \\
\hline & & (10) & .5236 & & & (10) & .6997 & & & (10) & 4.6903 & & & (10) & 15.7369 \\
\hline & & (12) & .3457 & & & (12) & 2.7422 & & & (12) & 3.1203 & & & (12) & 10.9869 \\
\hline & & (1) & .6899 & & & (1) & 3.1250 & & & (1) & 5.7971 & & & (1) & 16.8194 \\
\hline & & (2) & .6895 & & & (2) & 3.1600 & & & (2) & 5.7983 & & & (2) & 15.2730 \\
\hline & & (16) & .6780 & & & (16) & 3.1629 & & & (16) & 5.7961 & & & (16) & 15.4563 \\
\hline & & (18) & .6789 & & & (18) & 3.1196 & & & (18) & 5.7850 & & & (18) & 15.2574 \\
\hline
\end{tabular}




\section{Implications for the UFRH as a Model of Forecasting Future Spot Rates}

What do the above VMR random coefficients alternatives, (8), (10), and (12) under the logarithmic change specification, imply for the UFRH as a model of forecasting future spot rates, given that the intercept is insignificantly different from zero? First, we can observe that the new model 8 differs from the original model 1 or $1^{\prime}$ in the error term only. Both models 8 and 1 or $1^{\prime}$ are simple linear regression models. The validity of the UFRH is assured provided that the constant coefficient, $\beta_{(R) m}$, in model 8 does not significantly differ from one and, simultaneously, $\sigma_{u(R) m}^{2}$ does not significantly differ from zero (which is not true for 64 or $21.3 \%$ of 300 cases considered). The random behavioral error in model 1 or $1^{\prime}$ is part of the composite error $w_{(R) m}(t)$ in model 8. The former is homoscedastic and has a constant variance, while the latter is heteroscedastic and has a variable and dynamic conditional variance. Based on model 8 , we can determine how the stochastic- disturbance force alone affects the movements of the currency beta when the economic force, $f_{m}(t)$, is absent.

Second, the new model 10 implies that the UFRH as a model of forecasting exchange rates is nonlinear, with two explanatory variables, $X_{m}(t-1)$ and $X_{m}^{*}(t-1)$, and a heteroscedastic composite error, $w_{(D) m}(t)$. Therefore, model 10 is a multiple nonlinear model in the presence of heteroscedasticity. In this case, the UFRH holds if $\beta_{(D) m}$ is not significantly different from one and, simultaneously, $\alpha_{(D) m}$ and $\sigma_{u(D) m}^{2}$ are not significantly different from zero. But we have found evidence (33\% of 300 cases) suggesting that these conditions are not satisfied jointly. That is, empirical evidence supports the argument in favor of using the nonlinear model 10 for forecasting future spot rates. If the multiple nonlinear model under the linear trend specification is valid, then the original UFRH is misspecified, implying that it is necessary to find additional variables and use a nonlinear form for improved exchange rate predictions. The linear trend specification suggests an additional explanatory variable, $X_{m}^{*}(t-1)$, meaning that the impact of $X_{m}(t-1)$ upon $Y_{(D)}(t)$ also depends on the trend variable $(t)$ in the forward market.

Third, similarly, the new model 12 of the quadratic trend formulation also implies that the UFRH as a model of forecasting 
exchange rates is nonlinear in the presence of three explanatory variables $X_{m}(t-1), X_{m}^{*}(t-1)$, and $X_{m}^{* *}(t-1)$, and a heteroscedastic composite error, $w_{(P) m}(t)$, implying that the rejection of the unbiasedness hypothesis of forward markets may be caused by the response of the future spot rate to structural changes in the same direction as the dynamic and stochastic beta responds to the trend situation summarized by $t$ and $t^{2}$. The UFRH is justified if $\beta_{(P) m}$ is not significantly different from one and, simultaneously, $\alpha_{(P) m}, \gamma_{(P) m}$, and

$\sigma_{u(P) m}^{2}$ are not significantly different from zero. We have found empirical evidence (31\% of 300 cases) against these conditions, suggesting that the original UFRH may involve a serious specification error. Under this situation, the thesis that the forward rate is an unbiased predictor of the future spot rate under both the level and percent change specifications is rejected empirically, in favor of the nonlinear VMR specifications (with a parabolic trend) under the logarithmic change specification.

In sum, a basic assumption underlying the original UFRH is that the ratio of the future spot rate to the forward rate is equal to the currency beta which remains fixed over time and does not significantly differ from one. In this theory, the forward rate is the only explanatory variable, the regression error is homoscedastic having a constant variance, and the functional form is linear. In contrast, the VMR versions based on the logarithmic change specification imply that the UFRH, as a model of currency forecasting, has a currency beta changing dynamically and stochastically through time, where the currency beta must be treated as a market-determined random variable. In the VMR versions, the forward premium is not necessarily the only explanatory variable, the regression error is heteroscedastic having a variable and dynamic conditional variance, and the functional form is nonlinear. The random and dynamic behavior of the currency beta can be put forward as an explanation for the empirical failure of the unbiasedness hypothesis. The VMR versions of random beta models that account for such changing behavior lead to improved forecasts of future spot rates.

\section{Concluding Remarks}

In this study I have tested the unbiased forward rate hypothesis (UFRH) and its implications for forecasting future spot rates by employing the 
logarithmic change specification and the variable mean response (VMR) random coefficients models. I have analyzed the possibility and nature of stochastic variation, nonstationarity, and shifts in the mean and variance parameters of currency betas of the logarithmic change specification treated as the VMR stochastic coefficients regressions. The VMR regressions are capable of reflecting the currency beta's behavioral adaptation in response to structural changes. Two forces are assumed to affect the currency beta. One force is the random disturbance with a zero conditional mean and a constant conditional variance and the other force is a (linear or parabolic) trend function of calendar time. The ability of the economic trend factor to drive the currency beta to be stochastically and dynamically unstable is stronger than that of the random disturbance force. The four-step generalized least squares (FGLS) procedure incorporating the Newey-West adjustment for the variance-covariance matrix was used to estimate the relevant parameters.

The currency beta of the forward premium under the logarithmic change specification was found to be purely random (without time variation) for $21.3 \%$ of the total cases reviewed. But we found no specific relationship between the length of the time horizon and the number of cases confirming the randomness hypothesis.

The currency beta was also found to display a linear or parabolic fluctuation for a significant number of cases. In the linear case, the null hypothesis of a constant and stationary beta was rejected for $33 \%$ of the 300 cases considered, while in the parabolic case, the percentage (31\%) decreases slightly. The number of cases with a significant trend path increases as the time horizon lengthens, but the number does not indicate any specific relationship with the length of the estimation period. The results indicate that the currency betas under the logarithmic change and VMR specifications display a persistent trend through time.

Consequently, out of 300 cases, there were only 44 cases (14.7\%) in which currency betas were found to be fixed rather than dynamic and stochastic.

Five special tests, called $T^{*}, B, S^{\prime}, G$, and $W$, were performed to capture the variance shift or heterogeneity of the currency beta. According to the $B, S^{\prime}$, and $W$ tests, the null hypothesis of variance homogeneity is firmly rejected. The $T^{*}$ and $G$ tests provided a weaker evidence compared with the other three tests. Nevertheless, the test results strongly suggest that variance shift or heterogeneity should be 
considered as another evidence of the dynamic and stochastic behavior of the currency beta affecting the unbiased forecasts of future spot rates.

These findings have significant implications for forecasting future spot rates. According to the various tests undertaken in this research, the currency beta moves randomly and dynamically over time and responds sensitively to trend conditions. The random and dynamic instability of the currency beta through time, as I have examined in detail, implies misspecifications of the standard UFRH and causes the unbiasedness hypothesis to be rejected. The unbiasedness hypothesis may be rejected simply because of the instability of the currency beta (the slope of the efficiency hypothesis). Therefore, it is both necessary and essential to fully comprehend the patterns of the dynamic and stochastic behavior of currency betas. The information concerning the nature of the dynamic and stochastic instability of the currency beta is of vital importance to capture the movement of foreign exchange rates and to improve the accuracy of foreign exchange rate forecasts. Using the logarithmic change specification, the present study delivers three VMR alternatives to the original UFRH for improved point forecasting of future spot rates.

In short, the FGLS estimates of currency betas based on the VMR specifications have led to the conclusion that currency betas are characterized by changing (mean and variance) and stochastic variations; they are not fixed. The currency beta of a currency is a linear (e.g., a linear trend) or a nonlinear (e.g., a quadratic trend) time series. The nature and sources of the underlying dynamics and stochastics in the time series are different from currency to currency. In contrast, the difficulty with OLS or SUR is that its estimates of currency betas are a constant applicable to all months in a time period (e.g., as illustrated by figures 1 and 2).

The empirical results have an important bearing on the issue of methodology. Both OLS and SUR have been widely used to test the UFRH because they are easy and simple to apply. However, both OLS and SUR are less appropriate than FGLS for testing the UFRH as a model of forecasting future spot rates in the complexities of the international economy.

It is noted that most of the modeling and statistical techniques used in this research are the same as those used in Lin, Chen, and Boot (1992) and Lin and Lin (2000), and that the principal issues investigated by the present study are parallel to those addressed by the studies of Lin, Chen, and Boot (1992) and Lin and Lin (2000). There, however, are 
distinct differences: this research and Lin and Lin are concerned with macroeconomic variables -- foreign exchange rates and stock returns at the national level, whereas the work of Lin, Chen, and Boot has been devoted to microeconomic variables -- stock returns at the firm's level; and these three studies are based on different theories having similar functional structures. These studies have demonstrated the power of statistical methodologies if appropriately applied and have transformed the same arts of modeling at the macro- and the microlevel. They are, therefore, enhanced by one another in a number of methodological aspects (estimation and test methods, modeling, forecasting, etc.). It is frequently agreed, that as a rule of thumb, the method of analysis must fit the choice of level. But the methodologies applied in this research may fit research issues at the microeconomic level and at the macroeconomic level, as well.

Finally, the dynamic and stochastic behavior of currency betas could be attributed to the dynamic behavior of various macroeconomic variables from different sectors of an economy, in addition to the trend variable. This could be an interesting project on its own. For example, the unexpected shocks of foreign exchange and interest rates from the financial sector, country stock return index from the real sector, and the balance of trade from the external sector, are potential choices for future extensions of this study. I am currently investigating such extensions.

\section{APPENDIX I. A Brief Description of The Four-Step Generalized Least Squares (FGLS) Procedure}

Details about the FGLS procedure [ Theil (1971) and Singh et al. (1976)] applied to the parabolically dynamic Model 12 are presented as follows. Equation 12 can be expressed in matrix form,

$$
y=Z B+w,
$$

where $y=$ the Mxl vector of observations on the dependent variable, $Y_{(P)}(t)$, $t=1, \ldots \mathrm{M} ; Z=\left[\begin{array}{cccc}1 & X & X^{*} & X^{* *}\end{array}\right]$, where $X, X^{*}$, and $X^{* *}$ are Mxl vectors of nonstochastic regressors,

$$
X(t-1), X^{*}(t-1)=t X(t-1)
$$


and

$$
X^{* *}(t-1)=t^{2} X(t-1),
$$

respectively; $B^{\prime}=\left(\beta_{0(p)}, \beta_{(p)}, \alpha_{(p)}, \gamma_{(p)}\right) ;$ and $w=$ the Mxl column vector of disturbances, $w_{(p)}(t)$ with $E(w)=0$ and

$$
E\left(w w^{\prime}\right)=A=\operatorname{diag}\left(a_{1}^{2}, \ldots, a_{M}^{2}\right)=\left[\begin{array}{cccc}
a_{1}^{2} & 0 & \ldots & 0 \\
0 & a_{2}^{2} & \ldots & 0 \\
\ldots & \ldots & \ldots & \ldots \\
0 & 0 & \ldots & a_{M}^{2}
\end{array}\right]
$$

where

$$
a_{t}^{2}=X^{2}(t-1) \sigma_{u(p)}^{2}+\sigma_{v(p)}^{2} .
$$

The method involves four steps and uses equation 3 as a time-series regression in the first step. Steps 1 and 2 are actually due to Theil (1971) and are also used by Fabozzi and Francis (1978) in their study of the randomness of beta.

Step 1 Form

$$
e_{t}^{2}=\sigma_{v(P)}^{2} P_{t}+\sigma_{u(P)}^{2} Q_{t}+\theta_{t}
$$

where $e_{t}=$ the $t$-th OLS residual obtained from (3); $P_{t}=1-P_{t}^{\prime}$ with

$$
P_{t}^{\prime}=X^{2}(t-1) / \sum_{t} X^{2}(t-1) ; Q_{t}=X^{2}(t-1)\left(1-2 P_{t}^{\prime}+Q_{0}^{\prime}\right),
$$

with

$$
Q_{0}^{\prime}=\sum_{t} X^{4}(t-1) /\left[\sum_{t} X^{2}(t-1)\right]^{2}
$$

and $\theta_{t}=$ the random deviation of $e_{t}^{2}$ from its own expectation with 
$E\left(\theta_{t}\right)=0$ and $\operatorname{Var}\left(\theta_{t}\right)=2\left(\sigma_{v(P)}^{2} p_{t}+\sigma_{u(P)}^{2} Q_{t}\right)^{2}$, implying that $\theta_{t}$ is heteroscedastic. Apply OLS to estimate (A2). Let the OLS estimators of $\sigma_{v(P)}^{2}$ and $\sigma_{u(P)}^{2}$ be $\hat{\sigma}_{v(P)}^{02}$ and $\hat{\sigma}_{u(P)}^{02}$, respectively.

Step 2 Define $\pi_{t}=1 / 2\left(\hat{\sigma}_{v(P)}^{02} P_{t}+\hat{\sigma}_{u(P)}^{02} Q_{t}\right)^{2} \quad$ and obtain the GLS estimators of $\sigma_{v(P)}^{2}$ and $\sigma_{u(P)}^{2}$, denoted by $\hat{\sigma}_{v(P)}^{2}$ and $\hat{\sigma}_{u(P)}^{2}$, respectively, via

$$
C \hat{\sigma}=\phi \text { or } \hat{\sigma}=C^{-1} \phi
$$

where

$$
C=\left[\begin{array}{cc}
\sum_{t} \pi_{t} P_{t}^{2} & \sum_{t} \pi_{t} P_{t} Q_{t} \\
\sum_{t} \pi_{t} P_{t} Q_{t} & \sum_{t} \pi_{t} Q_{t}^{2}
\end{array}\right], \hat{\sigma}=\left[\begin{array}{c}
\hat{\sigma}_{v(P)}^{2} \\
\hat{\sigma}_{u(P)}^{2}
\end{array}\right],
$$

and

$$
\phi=\left[\begin{array}{c}
\sum_{t} \pi_{t} P_{t} e_{t}^{2} \\
\sum_{t} \pi_{t} Q_{t} e_{t}^{2}
\end{array}\right] .
$$

$C^{-1}$ is an approximate variance-covariance matrix of $\hat{\sigma}$.

Step 3 use $\hat{\sigma}_{u(P)}^{2}$ and $\hat{\sigma}_{v(P)}^{2}$ to construct :

$$
\hat{a}_{t}^{2}=X^{2}(t-1) \hat{\sigma}_{u(P)}^{2}+\hat{\sigma}_{v(P)}^{2},
$$

and hence

$$
\hat{A}=\operatorname{diag}\left(\hat{a}_{1}^{2}, \ldots, \hat{a}_{M}^{2}\right) \text {. }
$$

Step 4 Obtain the GLS estimator $\hat{B}$ of $B$ in (A1), which is given by

$$
\hat{B}=\left(Z^{\prime} \hat{A}^{-1} Z\right)^{-1} Z^{\prime} \hat{A}^{-1} y,
$$

where $\left(Z^{\prime} \hat{A}^{-1} Z\right)^{-1}$ is taken as the variance-covariance matrix of $\hat{B}$. 
If the error in the equation or behavioral error, $v_{(p)}(t)$, is absent from equation 12, Singh et al. (1976) have also suggested a similar procedure: Step $1^{\prime}$ Form $T=I_{M}-Z\left(Z^{\prime} Z\right)^{-1} Z^{\prime}$ and $c=T y=T w$.

Then, form $\dot{c}, \dot{X}$, and $\dot{T}$, which are the vectors and matrix of squared elements of $c, X$, and $T$ respectively, and apply OLS to estimate $\dot{c}=g \sigma_{u(P)}^{2}+e$, where $g=\dot{T} \dot{X}$. Let the OLS estimator of $\sigma_{u(P)}^{2}$ be

$$
s_{u(P)}^{2}=\left(g^{\prime} g\right)^{-1} g^{\prime} \dot{c} .
$$

Hence,

$$
A^{*}=\operatorname{diag}\left(a_{1}^{* 2}, \ldots, a_{M}^{* 2}\right)
$$

with

$$
a_{t}^{* 2}=X^{2}(t-1) s_{u(p)}^{2}, t=1, \ldots, M .
$$

Step 2' Form $Q=T A^{\prime \prime} T$ and $\dot{Q}=$ the $M$ x $M$ matrix of the squared elements of $Q$.

It is shown that $E\left(e e^{\prime}\right)=2 \dot{Q}$, implying that $e$ is heteroscedastic.

Obtain a GLS estimator of $\sigma_{u(P)}^{2}$ given by:

$$
s_{u(P)}^{* 2}=\left(g^{\prime} \dot{Q}^{-1} g\right)^{-1} g^{\prime} \dot{Q}^{-1} \dot{c} .
$$

Step $3^{\prime}$ Use $s_{u(P)}^{* 2}$ to construct $\hat{A}^{*}=\operatorname{diag}\left(\hat{a}_{1}^{* 2}, \ldots, \hat{a}_{M}^{* 2}\right)$ with $\hat{a}_{t}^{*^{2}}=X^{2}(t-1) s_{u(P)}^{* 2}$. Step 4' Obtain the GLS estimator of $B$ given by :

$$
\hat{B}^{*}=\left(Z^{\prime} \hat{A}^{*-1} Z\right)^{-1} Z^{\prime} \hat{A}^{*-1} y .
$$

Similarly, the four-step GLS procedure was applied to estimate the pure randomness model 8 and the linearly dynamic model 10. In estimating models 8,10 , and 12 , both steps $1-4$ in the presence of $v_{(i)}(t)$ and steps $1^{\prime}-4^{\prime}$ in the absence of $v_{(i)}(t), i=R, D, P$ were applied.

It was found that if $\hat{\sigma}_{v(i)}^{2}$ from step 2 is insignificant, the results from 
steps 1 - 4 are very close to those from steps $1^{\prime}-4^{\prime}$. Since the estimates $\hat{\sigma}_{v(i)}^{2}$ are significantly different from zero, indicating the behavioral disturbance, $v_{(i)}(t)$, cannot be ignored, we reported only the results obtained by steps $1-4$.

\section{Appendix II. Tests for Variance Shift or Heterogeneity of Currency Betas}

In this appendix, five testing techniques for detecting variance shift or heterogeneity of betas are summarized. These are known to be the $T^{*}, B, G, S^{\prime}$, and $W$ tests. These tests were performed on the basis of the beta functions as given by (13) - (15). The existence of beta-variance shifts provides another evidence of dynamic and random instability of currency betas (slopes).

$T^{*}$ Test for Variance Shift

Let $\beta_{(i)}(t), i=R, D, P$ be given by (13) - (15), where $t=1, \ldots, M$, and $\bar{\beta}_{(i)}=\sum_{t=1}^{M} \beta_{(i)}(t) / M$ be the simple mean of $\beta_{(i)}(t)$. To save space, I shall omit index (i) .

Define

$$
b(t)=[\beta(t)-\bar{\beta}]^{2},
$$

and

$$
T=\left[\sum_{t=1}^{M}(t-1) b(t)\right] /\left[(M-1) \sum_{t=1}^{M} b(t)\right], 0 \leq T \leq 1
$$

Then, the $T^{*}$ test statistic [Hsu (1977)] for testing scale shift of beta can be described as

$$
T^{*}=(T-1 / 2) /[(M+1) / 6(M-1)(M+2)]^{1 / 2} .
$$

Under the null hypothesis of no variance shift (the constant variance or variance homogeneity hypothesis), $T^{*}$ can be approximated by the standard normal variable as $M$ is large. 


\section{$B, G, S^{\prime}$ and $W$ Tests for Variance Heterogeneity}

The test statistics, $B, G, S^{\prime}$, and $W$, for the detection of variance shifts, are developed based on grouped data. First, we present the $B$ test due to Bartlett (1937), which is a modified version of the log-likelihood ratio test. The $M$ values of $\beta(t)$ are divided into $K$ groups, each containing $n_{k}$ values such that $\sum_{k=1}^{K} n_{k}=M$. Let $\beta(k h)$ denote the $h$-th value of $\beta(t)$ in the $k$-th group and $\bar{\beta}(k)=\sum_{h=1}^{n_{k}} \beta(k h) / n_{k}$ be the simple average of the $k$-th group. Then, we have

$$
B=\left(-c^{-1}\right) \sum_{k=1}^{K}\left(n_{k}-1\right) 1 n\left(S_{k}^{2} / S^{2}\right)
$$

where

$$
\begin{gathered}
S_{k}^{2}=\sum_{h=1}^{n_{k}}[\beta(k h)-\beta(k)]^{2} /\left(n_{k}-1\right), \\
S^{2}=\sum_{k=1}^{K}\left(n_{k}-1\right) S_{k}^{2} / \sum_{k=1}^{K}\left(n_{k}-1\right),
\end{gathered}
$$

and

$$
c=1+[1 / 3(K-1)]\left[\sum_{k=1}^{K}\left(1 /\left(n_{k}-1\right)\right)-\left(1 / \sum_{k=1}^{K}\left(n_{k}-1\right)\right)\right] .
$$

Under the null hypothesis of variance homogeneity, $B$ is asymptotically distributed as $\chi^{2}(K-1)$. The approximation is good for large as well as small samples, but the test is sensitive to the departure from normality [cf. Layard (1973) and Brown and Forsythe (1974). Both the $T^{*}$ and $B$ tests are sensitive to the departure from the model assumption]. The $G, S^{\prime}$, and $W$ tests aim at reducing the sensitivity to non-normality. We now turn to these improved test statistics.

Let $n_{k}$ values of $\beta(t)$ in the $k$-th group be further divided randomly into $J_{k}$ subgroups, each containing $m_{k^{\prime}}$ values such that $\sum_{k^{\prime}=1}^{J_{k}} m_{k^{\prime}}=n_{k}$; let $\beta\left(k k^{\prime} s\right)$ denote the $s$-th value in the $k^{\prime}$-th subgroup of the $k$-th group; and let 


$$
\bar{\beta}\left(k k^{\prime}\right)=\sum_{s=1}^{m_{k^{\prime}}} \beta\left(k k^{\prime} s\right) / m_{k^{\prime}}
$$

and

$$
S_{k k^{\prime}}^{2}=\sum_{s=1}^{m_{k^{\prime}}}\left[\beta\left(k k^{\prime} s\right)-\bar{\beta}\left(k k^{\prime}\right)\right]^{2} /\left(m_{k^{\prime}}-1\right)
$$

denote the simple average and sample variance of the values contained in the $k^{\prime}$-th subgroup of the $k$-th group, respectively. Finally, define

$$
Y_{k k^{\prime}}=1 n S_{k k^{\prime}}^{2}, \bar{Y}_{k}=\sum_{k^{\prime}=1}^{J_{k}} Y_{k k^{\prime}} / J_{k},
$$

and

$$
\bar{Y}=\sum_{k}^{K} \sum_{k^{\prime}}^{J_{k}} Y_{k k^{\prime}} / \sum_{k=1}^{K} J_{k} .
$$

Then the Bartlett-Kendall's (1946) $G$ test statistic is given by:

$$
G=\frac{\sum_{k=1}^{K} J_{k}\left(\bar{Y}_{k}-\bar{Y}\right)^{2} /(K-1)}{\left[\sum_{k}^{K} \sum_{k^{\prime}}^{J_{k}}\left(Y_{k k^{\prime}}-\bar{Y}_{k}\right)^{2} / \sum_{k=1}^{K}\left(J_{k}-1\right)\right]}
$$

which, under the null hypothesis, is approximately distributed according to an $F$ variable with degrees of freedom $(K-1)$ and $\sum_{k=1}^{K}\left(J_{k}-1\right)$, for large $J_{k}$.

To describe the $S^{\prime}$ statistic proposed by Layard (1973), define

$$
q=\left\{\frac{\left(\sum_{k=1}^{K} n_{k}\right)\left[\sum_{k=1}^{K} \sum_{h=1}^{n_{k}}(\beta(k h)-\bar{\beta}(k))^{4}\right]}{\left[\sum_{k=1}^{K} \sum_{h=1}^{n_{k}}(\beta(k h)-\bar{\beta}(k))^{2}\right]^{2}}\right\}-3,
$$

which is a measure of the sample kurtosis used to correct the bias due to 
potential non-normality, $\bar{n}=\sum_{k=1}^{K} n_{k} / K$ and $g^{2}=2+[1-(1 / \bar{n})] q$. These lead to the $S^{\prime}$ statistic:

$$
S^{\prime}=\frac{\sum_{k=1}^{K}\left(n_{k}-1\right)\left[1 n S_{k}^{2}-\sum_{k=1}^{K}\left(n_{k}-1\right) 1 n S_{k}^{2} / \sum_{k=1}^{K}\left(n_{k}-1\right)\right]^{2}}{g^{2}}
$$

where $S_{k}^{2}$ is as defined in (A2). Under the null hypothesis, $S^{\prime}$ is asymptotically distributed as $\chi^{2}(K-1)$ for large $n_{k}$.

Finally, the $W$ statistic developed by Brown and Forsythe (1974) requires to define $Z_{k h}=\left|\beta(k h)-\bar{\beta}^{(\epsilon)}(k)\right|$, where $\bar{\beta}^{(\epsilon)}(k)$ is the mean of the beta values in the $k$-th group after trimming the largest and smallest $100 \in$ percent values, and $\in$ is set equal to .1 ,

$$
\bar{Z}_{k}=\sum_{h=1}^{n_{k}} Z_{k h} / n_{k} \text { and } \bar{Z}=\sum_{k=1}^{K} \sum_{h=1}^{n_{k}} Z_{k h} / \sum_{h=1}^{K} n_{k} .
$$

Then, the $W$ test statistic is given by

$$
W=\frac{\left[\sum_{k=1}^{K} n_{k}\left(\bar{Z}_{k}-\bar{Z}\right)^{2} /(K-1)\right]}{\left[\sum_{k=1}^{K} \sum_{h=1}^{n_{k}}\left(Z_{k h}-\bar{Z}_{k}\right)^{2} / \sum_{k=1}^{K}\left(n_{k}-1\right)\right]}
$$

which, for large $n_{k}$ and under the null hypothesis, is approximately distributed according to an $F$ variate with degrees of freedom $K-1$ and $\sum_{k=1}^{K}\left(n_{k}-1\right)$.

Note that the trimmed mean is designed to reduce the sensitivity to nonnormality, like q defined before. $\epsilon=.1$ has been shown to be most adequate for testing variance heterogeneity in random variables with symmetric fat-tailed distributions while $\epsilon=.5$ is most useful for skewly distributed random variables. Here it is conjectured that $\beta(t)$ is likely to belong to the family of 
the former. To examine the effect of $\in$, trials using $\epsilon=.3$ and .5 were also performed. The results did not change the conclusion based on $\in=.1$.

The above tests are designed for changes in the variance occurring at unknown points of time. If the possible shift points are known precisely, traditional tests for variance homogeneity may be applied. In reality, the possible change points are not known. Also, note that while these tests have been defined to test the same statistical hypothesis (the null hypothesis of variance homogeneity against the alternative hypothesis of variance shift or heterogeneity), they do not necessarily lead to the same conclusion. This is simply because each test technique has its own special assumption(s) and reacts differently to the violation of the normality assumption. Of course, a unanimous conclusion by all tests is most desirable.

\section{References}

Baillie, R. T., and Bollerslev, T. 1989. Common stochastic trends in a system of exchange rates. Journal of Finance 44: 167-181.

Barnhart, S. W., and Szakmary, A. C. 1991. Testing the unbiased forward rate hypothesis: evidence on unit roots, co-integration, and stochastic coefficients. Journal of Financial and Quantitative Analysis 26: 245-267.

Barnhart, S. W.; McNown, R.; and Wallace, M.S. 1999. Non-information tests of the unbiased forward exchange rate. Journal of Financial and Quantitative Analysis 34: 265-291.

Bartlett, M. S. 1937. Properties of sufficiency and statistical tests. Proceedings of the Royal Society of London, Series A 160: 268-282.

Bartlett, M. S., and Kendall, D. G. 1946. The statistical analysis of variance -heterogeneity and the logarithmic transformation. Supplements to the Journal of the Royal Statistical Society: 128-138.

Bekaert, G., and Hodrick, R. J. 1993. On biases in the measurement of foreign exchange risk premiums. Journal of International Money and Finance 12: 115-138.

Belsley, D.A., and Kuh, E. 1973. Time-varying parameter structures: An overview. Annals of Economic and Social Measurement 2: 375-378.

Bhawnani, V., and Kadiyala, K. R. 1977. Forecasting foreign exchange rates in developing economies. Applied Economics 29: 51-62.

Bilson, J. F. O. 1981. The speculative efficiency hypothesis. Journal of Business 54: 435-451.

Booth, G. G., and Mustafa, C. 1991. Long-run dynamics of black and official exchange rates. Journal of International Money and Finance 10: 392-405.

Boothe, P., and Longworth, C. 1986. Foreign exchange market efficiency tests: implications of recent empirical findings. Journal of International Money and Finance 5: 135-152. 
Brown, M. B., and Forsythe, A. B. 1974. Robust tests for the equality of variances. Journal of the American Statistical Association 69: 364-367.

Cheung, Y. W. 1993. Exchange rate risk premiums. Journal of International Money and Finance 12: 182-194.

Chiang, T. C., and Chiang, M. C. 1987. Forward rate, spot rate, and market efficiency--An empirical analysis of the Japanese yen. Review of Business and Economic Research 22: 57-67.

Chiang, T. C. 1988. The forward rate as a predictor of the future spot rate -- A stochastic coefficient approach. Journal of Money, Credit, and Banking 20: 212-232.

Choi, J. J.; Hiraki, T.; and Takezawa, N. 1998. Is foreign exchange risk priced in the Japanese stock market? Journal of Financial and Quantitative Analysis 33: 361-382.

Collins, D. W.; Ledolter, J.; and Rayburn, J. 1987. Some further evidence on the stochastic properties of systematic risk. Journal of Business 60: 425-448.

Cornell, B. 1977. Spot rates, forward rates, and exchange market efficiency. Journal of Financial Economics 5: 55-65.

Dickey, D. A., and Fuller, W. A. 1979. Distribution of the estimators for autoregressive time series with a unit root. Journal of the American Statistical Association 74: 427-431.

Dickey, D. A., and Fuller, W. A. 1981. Likelihood ratio statistics for autoregressive time series with a unit root. Econometrica 49: 1057-1072.

Dickey, D. A., and Pantula, S. G. 1987. Determining the order of differencing in autoregressive processes, Journal of Business \& Economic Statistics 5: 455-461.

Domowitz, I., and Hakkio, C. S. 1985. Conditional variance and the risk premium in the foreign exchange market. Journal of International Economics 19: 47-66.

Edwards, S. 1982. Exchange rates and 'news': A multi-currency approach. Journal of International Money and Finance 1: 211-224.

Engel, C., and Hamilton, J. D., 1990. Long swings in the dollar: Are they in the data and do markets know it? American Economic Review 80: 689-713.

Fabozzi, F. J., and Francis, J. C. 1978. Beta as a random coefficient. Journal of Financial and Quantitative Analysis 13: 101-116.

Fama, E. F. 1984. Forward and spot exchange rates. Journal of Monetary Economics 14: 319-338.

Ghysels, E. 1998. On stable factor structures in the pricing of risk: Do timevarying beta help or hurt? Journal of Finance 53: 549-573.

Giddy, I. H., and Dufey, G. 1975. The random behavior of flexible exchange rates: Implications for forecasting. Journal of International Business Studies 6: 1-33.

Gregory, A. W., and McCurdy, T. H. 1984. Testing the unbiasedness hypothesis in the forward foreign exchange market: A specification analysis. Journal of International Money and Finance 3: 357-368. 
Hansen, L. P., and Hodrick, R. J. 1980. Forward exchange rates as optimal predictors of future spot rates: An econometric analysis. Journal of Political Economy 88: 829-853.

Hansen, L. P., and Hodrick, R. J. 1983. Risk-averse speculation in the foreign exchange market: An econometric analysis of linear models. In J. A. Frenkel (ed.). Exchange Rates and International Economics. Chicago, Il: University of Chicago Press for the National Bureau of Economic Research: 113-152.

Hildreth, C., and Houck, J. P. 1968. Some estimators for a linear model with random coefficients. Journal of the American Statistical Association 63: 584-595.

Hsieh, D. A. 1984. Tests of rational expectations and no-risk premium in forward exchange markets. Journal of International Economics 18: 173184.

Hsu, D. A. 1977. Tests for variance shift at an unknown time point. Applied Statistics 26: 279-284.

Kaminsky, G., and Peruga, R. 1990. Can a time-varying risk premium explain excess returns in the forward market for foreign exchange? Journal of International Economics 24: 47-70.

Kohlhagen, S. W. 1975 The performance of the foreign exchange markets: 1971-1974. Journal of International Business Studies 6: 33-39.

Kohlhagen, S. W. 1979. The forward rate as an unbiased predictor of the future spot rate. Columbia Journal of World Business 14:77-85.

Layard, M. W. J. 1973. Robust large-sample tests for homogeneity of variances. Journal of the American Statistical Association 68: 195-198.

Levich, R. M. 1979a. Are forward exchange rates unbiased predictors of future spot rates? Columbia Journal of World Business 14: 49-61.

Levich, R. M. 1979b. On the efficiency of markets for foreign exchange. Chapter 7. In R. Dornbusch and J. A. Frenkel (eds.). International Economic Policy: Theory and Evidence. Baltimore, MD: Johns Hopkins University Press: 246-266.

Lewis, K. K. 1989. Changing beliefs and systematic rational forecast errors with evidence from foreign exchange. American Economic Review 79: 621-636.

Lin, W. T; Chen, Y. H.; and Boot, J. C. 1992. The dynamic and stochastic instability of betas: Implications for forecasting stock returns. Journal of Forecasting 11: 517-541.

Lin, W. T., and Chen, Y. H. 1998. Forecasting foreign exchange rates with an intrinsically non-linear dynamic speed of adjustment model. Applied Economics 30: 295-312.

Lin, H. J., and Lin, W. T. 2000. A dynamic and stochastic beta and its implications in global capital markets. International Finance 3:123-160.

Longworth, D. 1981. Testing the efficiency of the Canadian-U. S. exchange market under the assumption of no-risk premium. Journal of Finance 36: 43-49. 
Meese, R. A., and Singleton, K. J. 1982. On the unit roots and the empirical modeling of exchange rates. Journal of Finance 37: 1029-1035.

Newey, W. K., and West, K. D. 1987. A simple, positive semi-definite, heteroskedasticity and autocorrelation consistent covariance matrix. Econometrica 55: 703-708.

Pagan, A. 1980. Some identification and estimation results for regression models with stochastically varying coefficients. Journal of Econometrics 13: 341-363.

Perron, P. 1988. Trends and random walks in macroeconomic time series, further evidence from a new approach. Journal of Economic Dynamics \& Control 12: 297-332.

Phillips, P. C. B., and Perron, P. 1988. Testing for a unit root in time series regression. Biometrika 75: 335-346.

Raj, B., and Ullah, A. 1981. Econometrics: A Varying Coefficients Approach. New York, NY: St. Martins Press.

Rosenberg, B. 1973. A survey of stochastic parameter regression. Annals of Economic and Social Measurement 2: 381-397.

Siegel, J. J. 1972. Risk, interest rates, and forward exchange. Quarterly Journal of Economics 86: 303-309.

Singh, B.; Nagar, A. L.; Choudhry, N. K.; and Raj, B. 1976. On the estimation of structural change: A generalization of the random coefficients regression model. International Economic Review 17: 340-361.

Taylor, M. 1995. The economics of exchange rates. Journal of Economic Literature 33: 13-47.

Theil, H. 1971. Principles of Econometrics. New York, NY: John Wiley \& Sons.

Wolff, C. C. P. 1987a. Forward foreign exchange rates, expected spot rates, and premia: A signal-extraction approach. Journal of Finance 42: 395-406.

Wolff, C. C. P. 1987b. Time-varying parameters and the out-of-sample forecasting performance of structural exchange rate models. Journal of Business \& Economic Statistics 5: 87-97. 